\title{
SOME UNPLEASANT GENERAL EQUILIBRIUM IMPLICATIONS OF EXECUTIVE INCENTIVE COMPENSATION CONTRACTS
}

\author{
John B. Donaldson \\ Natalia Gershun \\ Marc P. Giannoni \\ Working Paper 15165 \\ http://www.nber.org/papers/w15165 \\ NATIONAL BUREAU OF ECONOMIC RESEARCH \\ 1050 Massachusetts Avenue \\ Cambridge, MA 02138 \\ July 2009
}

The views expressed herein are those of the author(s) and do not necessarily reflect the views of the National Bureau of Economic Research.

NBER working papers are circulated for discussion and comment purposes. They have not been peerreviewed or been subject to the review by the NBER Board of Directors that accompanies official NBER publications.

(C) 2009 by John B. Donaldson, Natalia Gershun, and Marc P. Giannoni. All rights reserved. Short sections of text, not to exceed two paragraphs, may be quoted without explicit permission provided that full credit, including (C) notice, is given to the source. 
Some Unpleasant General Equilibrium Implications of Executive Incentive Compensation Contracts

John B. Donaldson, Natalia Gershun, and Marc P. Giannoni

NBER Working Paper No. 15165

July 2009

JEL No. E32,J33

\begin{abstract}
We consider a simple variant of the standard real business cycle model in which shareholders hire a self-interested executive to manage the firm on their behalf. Delegation gives rise to a generic conflict of interest mediated by a convex (option-like) compensation contract which is able to align the interests of managers and their shareholders. With such a compensation contract, a given increase in the firm's output generated by an additional unit of physical investment results in a more than proportional increase in the manager's income. We find that incentive contracts of this form can easily result in an indeterminate general equilibrium, with business cycles driven by self-fulfilling fluctuations in the manager's expectations. These expectations are unrelated to fundamentals. Arbitrarily large fluctuations in macroeconomic variables may possibly result.
\end{abstract}

John B. Donaldson

Columbia Business School

3022 Broadway, Uris Hall

New York, NY 10027-6902

jd34@columbia.edu

Natalia Gershun

Pace University

Lubin School of Business

1 Pace Plaza

New York, NY 10038.

ng65@columbia.edu
Marc P. Giannoni

Columbia Business School

3022 Broadway, Uris Hall 824

New York, NY 10027-6902

and NBER

mg2190@columbia.edu 


\section{Introduction}

Informed by principal-agent theory, corporate boards have sought to develop managerial compensation packages with stronger links between pay and performance. Stock options, in particular, are perceived as providing one such link, and have emerged as the single largest component of U.S. executive compensation. According to Hall and Murphy (2002), "in fiscal 1999, 94\% of S\&P 500 companies granted options to their top executives. Moreover, the grant-date value of stock options accounted for $47 \%$ of total pay for S\&P 500 CEOs in 1999." CEOs of the largest U.S. companies frequently receive annual stock option awards that are on average larger than their salaries and bonuses combined. ${ }^{1}$ Executive options contracts represent a particular instance of a highly non-linear convex style contract. ${ }^{2}$

In this paper we demonstrate that convex executive pay practices, within the context of the separation of ownership and control in the modern corporation, may have dramatic, adverse business cycle consequences. In particular, we show that convex compensation contracts, which are broadly typical of U.S. CEO pay practices, give rise to generic sunspot equilibria in otherwise standard dynamic stochastic general equilibrium (DSGE) modeling frameworks. Sunspot equilibria (indeterminacy) formalize the notion that expectations not grounded in fundamentals may lead to behavior by which they are fulfilled. These equilibria may involve arbitrarily large fluctuations in macroeconomic variables even though production is characterized by constant returns to scale at the social as well as private level. As such, convex managerial compensation contracts provide an entirely new mechanism by which indeterminacy may arise in real (non-monetary) economies. An even more disturbing observation is that convex contracts may lead, under certain parameter configurations, to non-stationary behavior. Practically speaking this means that optimal contracts may induce the self-interested manager to adopt investment policies that drive his firm's equilibrium

\footnotetext{
${ }^{1}$ See Jensen and Murphy (1990); also, Shleifer and Vishny (1997) and Murphy (1999).

${ }^{2}$ More recently, corporate boards have expanded the range of incentive instruments to include other forms of equity based incentive pay (e.g., direct stock grants). This has gone hand-in-hand with a steady reduction in the salary component of executive pay. For March 2007, Mercer Consulting reports that equity related incentive pay represents $2 / 3$ of total compensation (average of 1000 largest U.S. firms by sales). Cash salary compensation represents only 19\%. (For both statistics see www.mercer.com, "Study of CEO Compensation Trends," May 15th, 2008.) Taken together, the various equity-related components remain, in value terms, highly convex functions of the standard measures of firm financial performance.
} 
capital stock to zero. ${ }^{3}$

Sunspot equilibria have previously been studied in one-sector dynamic equilibrium models with external effects or monopolistic competition coupled with some degree of increasing returns. ${ }^{4}$ In one-sector models with increasing returns, if all agents simultaneously decide, based on a nonfundamental belief shock, to increase their investment in an asset above the level associated with the initial equilibrium, the rate of return on that asset tends to increase, justifying the higher level of investment and validating agents' beliefs. The main objection to this literature has been its empirical implausibility because of the relatively large increasing returns required to sustain the sunspot equilibria. Empirical estimates, furthermore, suggest that aggregate returns to scale seem to be constant, if not decreasing. ${ }^{5}$ In Wen's (1998) one-sector production model with variable capacity utilization of capital stock, indeterminacy occurs with significantly lower level of increasing returns. But the ability of the representative agent to alter capacity utilization in response to shock realization produces counterfactually smooth, in fact almost constant, aggregate consumption.

Indeterminacy can also arise in models with multiple production sectors if returns to scale differ at the social and private levels. Benhabib and Farmer (1996) demonstrate that indeterminacy occurs in a two-sector model with small, sector-specific external effects and very mild increasing returns at the aggregate level, while the private returns are constant. Perli (1998) obtains similar results by introducing home production. The argument against multi-sector models with aggregate increasing returns is that they imply a convex-to-the-origin production possibility frontier at the social level, which means that sectoral aggregate supply curves are negatively sloped. In Benhabib, Meng and Nishimura (2000) multiple equilibria arise in multisector economies with constant social returns in all sectors combined with minor external effects in some sectors. To generate indeterminacy in this latter model decreasing returns are necessary at the level of private firms with the implication that firms earn positive profits. Some kind of fixed cost is then needed to forestall potential new

\footnotetext{
${ }^{3}$ Financial firms seem especially prone to lavishly convex compensation practices. We are reminded of the financial crises surrounding the collapse of LTCM. In the year preceding its bankruptcy, the partners took the deliberate decision to reduce the firm's capital, as a device for maximizing returns. More recently (2008) highly convex managerial compensation at various investment banks was observed in parallel with their bankruptcy. We are viewing these compensation contracts as highly convex to either the firm's stock price or its dividend (or distributions to investors in the case of hedge funds).

${ }^{4}$ Schmitt-Grohe (1997) compares four prominent models with these features.

${ }^{5}$ See Basu and Fernald (1997) and Laitner and Stolyarov (2004).
} 
entrants.

In multi-sector models, increasing the relative price and the output of the capital good can also lead to an increase of its marginal product if the production of the capital good is relatively more capital intensive. When combined with market distortions and external effects, the rise in the capital stock may not be enough to offset the initial increase of its marginal product. Both the stock and the marginal product of capital rise simultaneously, mimicking the effect of increasing returns in a one-sector model.

In addition, models of endogenous firm entry and exit decisions and models with a variable degree of competition can also give rise to equilibrium indeterminacy (Jaimovich, 2007). In monetary models, an indeterminate equilibrium can arise in the case that monetary policy is conducted by following, e.g., an interest-rate rule not satisfying the so-called Taylor principle (see, e.g., Clarida, Galí and Gertler, 2000; Woodford, 2003), or, alternatively, in the case that a sufficiently large fraction of households do not participate in asset markets (Bilbiie, 2008).

In contrast, the model considered in this paper does not need aggregate increasing returns, a difference between social and private returns to scale, a variable degree of competition, or monetary phenomena to generate multiple equilibria. In our economy with delegated management and a convex executive compensation contract, the wedge between the actual return on capital and the return on capital as experienced by the manager is at the heart of the indeterminacy result. The power (degree of convexity) of the performance portion of the executive compensation contract tends to magnify the effective rate of return on capital from the manager's perspective. As a result, the expectation of a high return on capital may increase the income of the manager so much next period that consumption smoothing considerations dictate a diminished level of investment today, thereby fulfilling the high return expectation. Nevertheless, our analytical and numerical results reveal that the degree of contract convexity required for indeterminacy is very low, especially so relative to a standard call options style incentive contract.

An outline of the paper is as follows: Section 2 describes the model, and defines equilibrium. Section 3 provides the theoretical basis for the analysis of convex contracts within the assumed model context. Section 4 analyzes equilibrium and details the precise circumstances under which indeterminacy and instability arise. Section 5 provides an overview of the procedure by which 
equilibrium is computed numerically and applies this methodology to the study of the economy's business cycle characteristics. Section 6 concludes.

\section{A General Equilibrium Model of Delegated Management}

We focus on the context of a better informed, self-interested manager and the shareholder-workers on whose behalf he undertakes the firm's investment and hiring decisions in light of his compensation contract. The total population measure is $1+\mu$, of which a measure $\mu$ are managers (collectively referred to as "the manager") and a measure one are shareholder-workers. ${ }^{6}$

\section{$2.1 \quad$ Agents}

\subsubsection{The Representative Consumer-Worker-Shareholder}

The representative consumer-worker-shareholder's objective is to maximize his expected life-time utility over consumption and leisure by choosing the fraction of the time endowment, $n_{t}^{s}$, he wishes to work and selecting his next period's investment in a vector of financial assets, $z_{t+1}=\left(z_{t+1}^{e}, z_{t+1}^{b}\right)$, he wishes to hold; his decision problem reads as:

$$
V^{s}\left(z_{0}^{e}, z_{0}^{b}\right)=\max _{\left\{z_{t+1}^{e}, z_{t+1}^{b}, n_{t}^{s}\right\}} E_{0}\left[\sum_{t=0}^{\infty} \beta^{t} u^{s}\left(c_{t}^{s}, 1-n_{t}^{s}\right)\right], \quad \text { where } 0<\beta<1
$$

subject to:

$$
\begin{aligned}
c_{t}^{s}+q_{t}^{e} z_{t+1}^{e}+q_{t}^{b} z_{t+1}^{b} & =\left(q_{t}^{e}+d_{t}\right) z_{t}^{e}+w_{t} n_{t}^{s}+z_{t}^{b} \\
\left(q_{t+1}^{e}, q_{t+1}^{b}, w_{t+1}, d_{t+1}\right) & \sim d F\left(\ldots ; q_{t}^{e}, q_{t}^{b}, w_{t}, d_{t}\right) .
\end{aligned}
$$

In problem (1)-(3) above, $\beta$ is the subjective time discount factor, $c_{t}^{s}$ denotes period $t$ per capita shareholder-worker consumption, $w_{t}$ the period $t$ competitive wage rate and $u^{s}\left(c_{t}^{s}, 1-n_{t}^{s}\right)$ the consumer-worker-shareholder's period utility function. The expression $z_{t}^{e}$ represents his period $t$ equity asset holdings, chosen at time $t-1$, and priced in period $t$ at $q_{t}^{e} ; d_{t}$ denotes the period $t$ equity security's dividend. We choose $z_{t}^{b}$ to denote the amount of one period risk free discount

\footnotetext{
${ }^{6}$ This model is a version of that found in Danthine and Donaldson $(2008 \mathrm{a}, \mathrm{b})$.
} 
bonds held by the agent, and $q_{t}^{b}$ their period $t$ price. Shareholders are assumed to have rational expectations over the behavior of the economy's asset price, wage and dividend series. These are represented by $d F\left(\right.$ ). The shareholder-worker's information set, $I_{t}^{s}$, is given by

$$
I_{t}^{s}=\left\{\left(q_{\tau}^{e}, q_{\tau}^{b}, w_{\tau}, d_{\tau}, c_{\tau}^{s}, n_{\tau}^{s}, z_{\tau}^{e}, z_{\tau}^{b}\right) ; \tau \leq t\right\}
$$

Note that these agents lack information concerning the economy's capital stock; they will also be seen to lack information regarding total factor productivity, aggregate labor supplied, etc. ${ }^{7}$

The representative shareholder's preference ordering is given by:

$$
u^{s}\left(c_{t}^{s}, 1-n_{t}^{s}\right)=\frac{\left(c_{t}^{s}\right)^{1-\eta_{s}}}{1-\eta_{s}}-B \frac{\left(n_{t}^{s}\right)^{1+\zeta}}{1+\zeta}
$$

where $\eta_{s}$ denotes the representative shareholder's relative risk aversion coefficient $\left(0<\eta_{s}<\infty\right)$ and $\zeta$ is the inverse of the Frisch elasticity of labor supply $(0 \leq \zeta<\infty)$. Note that in the case of $\zeta=0$, the utility function in (4) reduces to the indivisible labor utility specification of Hansen (1985), while we obtain the case of fixed labor supply when $\zeta \rightarrow \infty$. Each consumer-worker-investor is endowed with one unit of time; in the special case where $\zeta=0$, the parameter $B(B>0)$ is chosen to allow the economy to match the fraction of that time devoted to work that is empirically observed.

Writing the shareholder's problem (1) - (4) in recursive form yields

$$
\begin{aligned}
V^{s}\left(z_{t}^{e}, z_{t}^{b} ; q_{t}^{e}, q_{t}^{b}, w_{t}, d_{t}\right)= & \max _{z_{t+1}^{e}, z_{t+1}^{b}, n_{t}^{s}}\left\{\frac{\left(c_{t}^{s}\right)^{1-\eta_{s}}}{1-\eta_{s}}-B \frac{\left(n_{t}^{s}\right)^{1+\zeta}}{1+\zeta}\right. \\
& \left.+\beta \int V^{s}\left(z_{t+1}^{e}, z_{t+1}^{b} ; q_{t+1}^{e}, q_{t+1}^{b}, w_{t+1}, d_{t+1}\right) d F()\right\}
\end{aligned}
$$

\footnotetext{
${ }^{7}$ In making these assertions, we appeal to the standard interpretation that shareholders are individually of measure zero and do not recognize they are identical to other shareholders. They thus do not identify their own labor supply with aggregate labor supply. Aggregate capital stock is revealed only if Tobin's $Q=1$. While this later requirement is formally the case in the simple model to be presented here, it can be voided by incorporating a small capital adjustment cost. Such a modification does not alter the form of the optimal contract, or the presence of equilibrium indeterminacy. Shareholders are not presumed to know the general form or specific parameter values of the firm's production function. Our model thus incorporates elements of moral hazard.
} 
where

$$
c_{t}^{s}=\left(q_{t}^{e}+d_{t}\right) z_{t}^{e}+w_{t} n_{t}^{s}+z_{t}^{b}-q_{t}^{e} z_{t+1}^{e}-q_{t}^{b} z_{t+1}^{b} .
$$

The necessary and sufficient first order conditions with respect to $n_{t}^{s}, z_{t+1}^{e}, z_{t+1}^{b}$ are

$$
\begin{aligned}
\left(c_{t}^{s}\right)^{-\eta_{s}} w_{t} & =B\left(n_{t}^{s}\right)^{\zeta} \\
q_{t}^{e} & =E_{t}\left[\frac{\left(c_{t+1}^{s}\right)^{-\eta_{s}}}{\left(c_{t}^{s}\right)^{-\eta_{s}}}\left(q_{t+1}^{e}+d_{t+1}\right)\right] \\
q_{t}^{b} & =E_{t}\left[\frac{\left(c_{t+1}^{s}\right)^{-\eta_{s}}}{\left(c_{t}^{s}\right)^{-\eta_{s}}}\right] .
\end{aligned}
$$

\subsubsection{The Firm}

On the production side, there is a single firm, acting as a stand-in for a continuum of identical, competitive firms. The firm produces output via a standard constant returns to scale Cobb-Douglas function:

$$
y_{t}=k_{t}^{\alpha}\left(n_{t}^{f}\right)^{1-\alpha} e^{\lambda_{t}}
$$

with two inputs - capital, $k_{t}$, and labor, $n_{t}^{f}-$ and the current level of technology $\lambda_{t}$; the latter is assumed to follow a stationary process, which we denote by $\lambda_{t+1} \sim d G\left(\lambda_{t+1} ; \lambda_{t}\right)$.

The evolution of the capital stock, $k_{t}$, follows:

$$
k_{t+1}=(1-\Omega) k_{t}+i_{t}, \quad k_{0} \text { given, }
$$

where $i_{t}$ is period $t$ investment and $\Omega, 0<\Omega<1$, the depreciation rate.

Since shareholders lack full information by which they can evaluate the manager's decisions, they endow him with a convex compensation contract. As will be fully explained in Section 3 , the main purpose of the contract is to align manager's interests with those of the investors who hire him. The manager does not receive hourly wages and therefore the labor-leisure trade-off is irrelevant for him. 


\subsubsection{The Manager}

At the beginning of period $t$, the manager privately observes the realization of the productivity parameter $\lambda_{t}$ and a vector $\nu_{t}$ of exogenous (sunspot) shocks which he believes are relevant to forecasting future events; he then takes his own utility maximizing decision $\left(c_{t}^{m}, i_{t}, n_{t}^{f}\right)$ in light of his remuneration contract. Here $c_{t}^{m}$ represents the manager's period $t$ consumption and $n_{t}^{f}$ the measure of shareholder-workers hired by the manager in period $t$. We assume initially that the manager's contract has the general form $g^{m}\left(h_{t}\right)$ where

$$
h_{t}=h\left(i_{t}, n_{t}^{f}, k_{t}, w_{t}, \lambda_{t}, \nu_{t}\right)
$$

is the measure of the firm's performance observed by the shareholders. Note that the shareholders do not observe the individual arguments of $h\left(\right.$ ). The manager's information set, $I_{t}^{m}$, is given by

$$
I_{t}^{m}=I_{t}^{s} \cup\left\{\left(c_{\tau}^{m}, i_{\tau}, n_{\tau}^{f}, k_{\tau}, w_{\tau}, \lambda_{\tau}, \nu_{\tau}, \bar{z}_{\tau}^{e}=1, \bar{z}_{\tau}^{b}=0\right) ; \tau \leq t\right\}
$$

where $\bar{z}_{t}^{e}, \bar{z}_{t}^{b}$ denote, respectively, the aggregate supplies of the indicated securities. In the absence of retained earnings, the manager's choice of $\left(i_{t}, n_{t}^{f}\right)$ yields dividends $d_{t}$ where

$$
d_{t}=y_{t}-n_{t}^{f} w_{t}-i_{t}-\mu g^{m}\left(h_{t}\right)
$$

Let $u^{m}$ ( ) be the manager's period utility of consumption function and let $H\left(\lambda_{t+1}, \nu_{t+1} ; \lambda_{t}, \nu_{t}\right)$ denote the joint probability distribution of $\left(\lambda_{t+1}, \nu_{t+1}\right)$ conditional on its period $t$ realization $\left(\lambda_{t}, \nu_{t}\right)$. The latter is known only to the manager.

The manager's problem then becomes:

$$
V^{m}\left(k_{0}, w_{0}, \lambda_{0}, \nu_{0}\right)=\max _{\left\{c_{t}^{m}, i_{t}, n_{t}^{f}\right\}} E_{0}\left[\sum_{t=0}^{\infty} \beta^{t} u^{m}\left(c_{t}^{m}\right)\right]
$$


subject to (8), (9), (10), (11), and ${ }^{8}$

$$
\begin{aligned}
c_{t}^{m} & \leq g^{m}\left(h_{t}\right) \\
c_{t}^{m}, n_{t}^{f} & \geq 0 \\
\left(\lambda_{t+1}, \nu_{t+1}\right) & \sim d H\left(\lambda_{t+1}, \nu_{t+1} ; \lambda_{t}, \nu_{t}\right) .
\end{aligned}
$$

Problem (12) has recursive representation

$$
\begin{aligned}
V^{m}\left(k_{t}, w_{t}, \lambda_{t}, \nu_{t}\right)= & \max _{i_{t}, n_{t}^{f}}\left\{u^{m}\left(g^{m}\left(h\left(i_{t}, n_{t}^{f}, k_{t}, w_{t}, \lambda_{t}, \nu_{t}\right)\right)\right)\right. \\
& \left.+\beta \int V^{m}\left(k_{t+1}, w_{t+1}, \lambda_{t+1}, \nu_{t+1}\right) d H\left(\lambda_{t+1}, \nu_{t+1} ; \lambda_{t}, \nu_{t}\right)\right\}
\end{aligned}
$$

with necessary and sufficient first order conditions: ${ }^{9}$

$$
u_{1}^{m}\left(c_{t}^{m}\right) g_{1}^{m}\left(h_{t}\right) h_{2}\left(i_{t}, n_{t}^{f}, k_{t}, w_{t}, \lambda_{t}, \nu_{t}\right)=0
$$

and

$$
\begin{aligned}
-u_{1}^{m}\left(c_{t}^{m}\right) g_{1}^{m}\left(h_{t}\right) h_{1}\left(i_{t}, n_{t}^{f}, k_{t}, w_{t}, \lambda_{t}, \nu_{t}\right)= & \beta \int V_{1}^{m}\left(k_{t+1}, w_{t+1}, \lambda_{t+1}, \nu_{t+1}\right) d H\left(\lambda_{t+1}, \nu_{t+1} ; \lambda_{t}, \nu_{t}\right) \\
= & \beta \int u_{1}^{m}\left(c_{t+1}^{m}\right) g_{1}^{m}\left(h_{t+1}\right)\left[h_{3}\left(i_{t+1}, n_{t+1}^{f}, k_{t+1}, w_{t+1}, \lambda_{t+1}, \nu_{t+1}\right)\right. \\
& \left.-h_{1}\left(i_{t+1}, n_{t+1}^{f}, k_{t+1}, w_{t+1}, \lambda_{t+1}, \nu_{t+1}\right)(1-\Omega)\right] \\
& \times d H\left(\lambda_{t+1}, \nu_{t+1} ; \lambda_{t}, \nu_{t}\right) .
\end{aligned}
$$

\footnotetext{
${ }^{8}$ Absent form the manager's decision problem is a participation constraint: in order to be induced to assume the role of the manager voluntarily, his welfare in that role must exceed his welfare as a shareholder-worker. This will be the case specifically when he is subject to an optimal contract. It is also true generically as we assume no disutility of work for the manager.

${ }^{9}$ These equations are necessary and sufficient provided the standard differentiability, concavity, and continuity restrictions are placed on $u^{m}()$, the production function and $d G()$. The distribution functions $H()$ and $G()$ are related by $d G\left(\lambda_{t+1} ; \lambda_{t}\right)=\int\left[\int d H\left(\lambda_{t+1}, \nu_{t+1} ; \lambda_{t}, \nu_{t}\right) d \nu_{t+1}\right] d \nu_{t}$. These are detailed in Danthine and Donaldson $(2008$ a).
} 
As with the shareholder-workers we specialize

$$
u^{m}\left(c_{t}^{m}\right)=\frac{\left(c_{t}^{m}\right)^{1-\eta_{m}}}{1-\eta_{m}}
$$

The manager need not be risk neutral nor have the same CRRA as the shareholder workers. By assumption, the manager does not participate in the capital markets, which are not complete. It is realistic to presume the manager is banned from trading the equity issued by the firm he manages. Not only does this rule protect shareholders from insider trading, but it also prevents the manager from using financial markets to mitigate the force of his contract. Restrictions on the ability of the executives to assume short positions in the stock of their own firms, or to adjust their long positions, are commonplace.

It is more controversial to assume that the manager cannot take a position in the risk free asset, although this assumption is common in the partial equilibrium contracting literature. We note, however, that under optimal contracting it will not be welfare-enhancing for the manager to trade risk free assets (or equity). Furthermore, in the context of non optimal contracts, suitable convexity still gives rise to sunspot equilibria, even in the presence of bond trading.

\subsection{Equilibrium}

Equilibrium in this economy for a given managerial contract $g^{m}\left(h_{t}()\right)$ is a triple of price functions $w_{t}=w\left(k_{t}, \lambda_{t}, \nu_{t}\right), q_{t}^{e}=q^{e}\left(k_{t}, \lambda_{t}, \nu_{t}\right), q_{t}^{b}=q^{b}\left(k_{t}, \lambda_{t}, \nu_{t}\right)$, an aggregate investment function $i_{t}=$ $i\left(k_{t}, \lambda_{t}, \nu_{t}\right)$, and an employment function $n_{t}=n\left(k_{t}, \lambda_{t}, \nu_{t}\right)$, such that:

1. The first order conditions of the representative consumer-worker-shareholder (5), (6), and (7), of the manager (14) and (15) are satisfied together with the constraints (2), (8), (9), (11), the manager's budget constraint (13) holding with equality, and the usual transversality condition: $\lim _{t \rightarrow \infty} \beta^{t} u_{1}^{m}\left(c_{t}^{m}\right) k_{t+1}=0$, for any given initial $k_{0}$.

2. The labor, goods and capital markets clear: $n_{t}^{s}=n_{t}^{f}=n_{t} ; y_{t}=i_{t}+c_{t}^{s}+\mu c_{t}^{m}$; and investors hold all outstanding equity shares, $z_{t}^{e}=1$, and all other assets (one period bonds) are in zero net supply, $z_{t}^{b}=0 .{ }^{10}$

\footnotetext{
${ }^{10}$ Equilibrium is easily shown to exist for this model.
} 
Note that in this economy, the shareholder-workers confront a large potential moral hazard problem vis-à-vis the manager because of the large information advantage the latter enjoys $\left(I_{t}^{s} \subset I_{t}^{m}\right)$. More typically, moral hazard is associated with unobservable managerial effort, in a context where effort is critical to production yet provided only at a disutility to the manager.

We have chosen to omit this feature for a number of reasons. First, recent events suggest that the effects of compensation agreements largely play themselves out via the firm's investment decision, something that is front and center for the entirety of our analysis. It seems likely that the 2007 - 2008 Wall Street bankruptcies were not due to insufficient managerial effort, at least in the narrow sense of the word, but to inappropriate investment policies. Second, if a disutility of effort term were added to the manager's period utility function, while also augmenting the production function with an "effort factor," the optimal contract becomes one in which the manager receives all the firm's net output $\left(w_{t} n_{t}+d_{t}\right)$, and pays a fee to the shareholders for the privilege of managing the firm. The existence of equilibrium indeterminacy is not affected by the addition of an effort decision.

\section{Convex Contracting}

We consider the family of contracts

$$
g^{m}\left(h_{t}()\right)=A+\left(h_{t}()\right)^{\theta}
$$

with $A, \theta$ constants, $A \geq 0, \theta>0$ and the measure of firm performance, $h_{t}(\mathrm{)}$ described by

$$
h_{t}()=\varphi \delta w_{t} n_{t}+\varphi d_{t}
$$

In expression (18), $\varphi$ and $\delta$ are constants satisfying $0<\varphi \leq 1,0 \leq \delta \leq 1$. The expression $w_{t} n_{t}$ denotes the equilibrium aggregate wage bill; $\delta$ represents the relative compensation weight applied to the wage bill vis-a-vis the dividend, and $\varphi$ the overall compensation scale parameter. Given appropriate restrictions on the values of the parameters $A, \theta, \delta, \varphi$, contracts of the form (17)-(18) are optimal within our model context. This assertion is summarized in the three theorems detailed 
below. Note that when focusing on first-order approximations, as we do in the next section, the equity price $q_{t}^{e}$ can be substituted for the dividend in the definition of $h_{t}$ ( ) without loss of optimality (although the coefficient $\varphi$ may need to be modified accordingly).

For simplicity, we assume $\mu=0$ in this section, although this is not required for most results.

Theorem 1 Suppose that $\eta_{s}$ and $\eta_{m}$ satisfy either $0 \leq \eta_{s}<1,0 \leq \eta_{m}<1$, or $1<\eta_{s}, 1<\eta_{m}$. Then the optimal contract is of the form (17)-(18) with $A=0, \theta=\frac{1-\eta_{s}}{1-\eta_{m}}>0, \delta=1$, and $0<\varphi \leq 1$. If, in addition, $\left|\eta_{m}-1\right|<\left|\eta_{s}-1\right|$, then the optimal contract is convex, $\theta>1$.

Proof. See Theorem 3 of Danthine and Donaldson (2008 a) for a formal proof. Appendix A presents an overview of the result.

The optimal contract must align the shareholders' and managers' stochastic discount factors. The basic intuition underlying Theorem 1 may be summarized as follows: in order for the delegated manager to select the investment and hiring plans preferred by the shareholder-workers, he must (i) be given an income stream with the same stochastic characteristics and (ii) he must be equally sensitive to these same income variations. ${ }^{11}$ By choosing $h_{t}()=\varphi w_{t} n_{t}+\varphi d_{t}$, where $n_{t} w_{t}$ denotes the aggregate wage bill, the first of these requirements is satisfied. By raising this quantity to the $\frac{1-\eta_{s}}{1-\eta_{m}}$ power, the marginal rate of substitution of the manager is made equivalent to that of the shareholder-workers in the context of the relevant intertemporal investment equation. For instance, if $0 \leq \eta_{s}<\eta_{m}<1$, then the shareholder-works ideally offers a convex compensation contract to the relatively risk-averse manager, in order to counteract the manager's strong concavity in preferences. In contrast, if $\eta_{m}>1$, contract convexity effectively induces the manager to behave in a more riskaverse fashion (see Danthine and Donaldson (2008 b), Corollary 3) so that the shareholder-worker offers a convex optimal contract to the manager when $1<\eta_{m}<\eta_{s}$. The constant $\varphi>0$ can be chosen to satisfy the manager's implicit participation constraint.

Theorem 2 Suppose that $\eta_{s}=\eta_{m}$. (i) Then the contract of the form (17)-(18) with $A=0, \theta=1$, $\delta=1$, and $0<\varphi \leq 1$ is optimal. (ii) There exist coefficients $A^{*}>0$ and $\varphi^{*}>0$ such that the

\footnotetext{
${ }^{11}$ The constant $\varphi$ can be chosen arbitrarily since $\mu=0$. With homogeneous utility and constant return to scale production, the manager will choose the same investment decisions irrespective of the scale of his income stream. It is thus not required that $\varphi=1$. In more general formulations, $\mu>0, \varphi$ is determined by the welfare weights assigned to the two agents in the Pareto formulation.
} 
contract in (i) can be arbitrarily well approximated by a contract of the form

$$
g^{m}\left(h_{t}()\right)=A^{*}+\varphi^{*} \bar{d}^{1-\theta^{*}} d_{t}^{\theta^{*}}
$$

for some $\theta^{*}=\theta^{*}\left(A^{*}\right)>1$. In general $\theta^{*}$ is a decreasing function of $A^{*}$. Note that (19) is also a special case of (17)-(18) where $\delta=0$ and $\varphi=\varphi^{*} \bar{d}^{1-\theta^{*}} \cdot{ }^{12,13}$

Proof. Part (i) follows as a special case of Theorem 1. Part (ii) is discussed in Danthine and Donaldson (2008 b).

In dynamic stochastic general equilibrium models such as the one considered here, dividends are countercyclical. This fact induces the manager to smooth out the firm's investment series much more than the shareholder-workers find optimal. To do otherwise would force the manager into a circumstance of very low consumption during cyclical upturns. The convexity of the contract overcomes the aforementioned disincentive and induces the manager to adopt a much more strongly pro-cyclical investment plan. The upshot of these considerations is simply that Part (ii) of Theorem 2 suggests that the degree of contract convexity may serve as a substitute for a suboptimal salary component and restore optimality.

What forms do observed managerial contracts actually have and do they resemble our theoretical constructs? As pointed out by Bolton and Dewatripont (2005, p. 157), "in most cases a manager's compensation package in a listed company comprises a salary, a bonus related to the firm's profits in the current year, and stock options (or other related forms of compensation based on the firm's share price). [...] In other words, the manager's remuneration can broadly be divided into a 'safe' transfer (the wage), a short term incentive component (the bonus), and a long term incentive component (the stock option)." ${ }^{14}$ In the notation of this paper, such managerial contracts can be

\footnotetext{
${ }^{12}$ In contract (19), $\bar{d}$ is the average free cash flow (dividend) when $\theta^{*}=1$. The term $\varphi^{*} \bar{d}^{1-\theta^{*}}$ is inserted to insure that the average manager's remuneration is little affected by the curvature parameter $\theta^{*}$.

${ }^{13}$ By arbitrarily well approximate we mean that the log-linear decision rules and the resultant detrended time series (business cycle) statistics are identical for properly selected $\theta^{*}$ and $\varphi^{*}$.

${ }^{14}$ One qualification to the general thrust of these remarks is the fact that convex contracting of the options related sort applies only to public companies. These account for roughly $50 \%$ of aggregate business capital in the U.S. (see McGrattan and Prescott (2007)) not the $100 \%$ our model implicitly assumes.
} 
generically characterized as

$$
g^{m}\left(h_{t}()\right)=A+A_{t}+\varphi d_{t}^{\theta}, \quad \text { with } \theta \geq 1
$$

with $A$ the constant payment, $A_{t}$ the variable 'bonus,' and $\varphi d_{t}^{\theta}$ the incentive component. To a first-order approximation, we may again express the incentive component in terms of the stock price instead of the dividend.

Within the context of this paper, managerial contracts precisely of form (20) do not, in general, lead to first best outcomes. While such contracts resemble the optimal contract described in Theorem 1, they are not identical as the aggregate wage bill does not enter into the quantity subject to the convexity parameter. This is not surprising: actual contracts do not recognize that shareholders are also workers and that their wage income must thus influence marginal rate of substitution formation.

How large is the degree of convexity in the compensation contract? Gabaix and Landier (2008) carefully study the link between firms' total market value (debt plus equity) and total compensation of the 1,000 highest paid CEOs in the U.S., from 1992 to 2004. Their compensation measure includes the following components: salary, bonus, restricted stock granted and Black-Scholes values of stock options granted. Using panel regressions, they find that the elasticity of CEO compensation to the firms' total market value is slightly above 1 (see their Table 2). While they do not formally reject an elasticity of 1 at the $5 \%$ confidence level, the point estimates lie above 1 in all specifications and are in some cases significantly larger than 1, at the $10 \%$ confidence level. Using the more aggregated compensation index of Jensen, Murphy, and Wruck (2004), which is based on all CEOs included in the S\&P 500, they estimate that an increase of $1 \%$ in the mean of the largest 500 firms' asset market values increases CEO compensation by $1.14 \%$ on average in the 1970-2003 sample (see their Table 3). Their Figure 1 suggests that this elasticity is sensibly larger in the 1990-2000 period. While we will focus our analysis on moderate levels of contract convexity, it is important to note that this convexity can easily be very large when the compensation involves call options. ${ }^{15}$

\footnotetext{
${ }^{15}$ To put our claim of 'mild convexity' in perspective, consider a standard call options contract where the degree of convexity is measured, using the Black-Scholes call valuation formulae, by gamma $(\Gamma)$. To award a manager a call option on his firm's stock is directly analogous to granting him a compensation contract of the form (20). Typically, the strike price of an options award is set equal to the then-prevailing stock price. The gamma of a long position in a
} 
With Theorems 1-2 in mind, we next explore the general equilibrium implications of economies where the manager is paid according to (17)-(18). In particular, we demonstrate that contracts of this form can easily generate sunspot equilibria by which we mean business cycle fluctuations driven by self-fulfilling managerial expectations. While optimal contracts cannot themselves create indeterminacy or instability (a result confirmed in Section 4.6), contracts with positive fixed payments or slightly excessive convexity easily can. It is to this latter family of contracts that Section 4 is addressed.

\section{Equilibrium Characterization}

\subsection{Preliminaries}

Substituting the various functional forms and definitions into the agent optimality equations and the market clearing conditions gives a set of equations, which the aggregate quantities $i_{t}, k_{t}, c_{t}^{m}, c_{t}^{s}, n_{t}$ etc. must satisfy in equilibrium. For the general family of contracts (17)-(18), they are as follows. Consumption of the manager and the shareholder depend on labor income and dividends

$$
\begin{aligned}
c_{t}^{m} & =A+\left(\varphi \delta w_{t} n_{t}+\varphi d_{t}\right)^{\theta} \\
c_{t}^{s} & =w_{t} n_{t}+d_{t},
\end{aligned}
$$

where dividends, in turn, relate to income and investment according to

$$
d_{t}=\alpha y_{t}-i_{t}-\mu A-\mu\left(\varphi \delta w_{t} n_{t}+\varphi d_{t}\right)^{\theta}
$$

The production function yields

$$
y_{t}=k_{t}^{\alpha} n_{t}^{1-\alpha} e^{\lambda_{t}}
$$

call option is always positive and reaches a maximum under this circumstance (for given volatility, time to expiration, etc.). Furthermore, as a function of the firm's stock price, an award of, say, 100,000 call options yields an overall contract convexity 100,000 times that of an individual call's gamma. We can imagine overall contract convexity becoming absurdly large. 
so that the real wage and the return on capital, $r_{t}$, are given by

$$
\begin{aligned}
w_{t} & =(1-\alpha)\left(y_{t} / n_{t}\right) \\
r_{t} & \equiv \alpha\left(y_{t} / k_{t}\right)+1-\Omega .
\end{aligned}
$$

The intratemporal first-order condition for the shareholder-worker optimal consumption-leisure decision is

$$
\left(c_{t}^{s}\right)^{-\eta_{s}} w_{t}=B n_{t}^{\zeta}
$$

While the above equations are all a-temporal, the equations determining the model's intertemporal dynamics are the capital accumulation equation

$$
k_{t+1}=(1-\Omega) k_{t}+i_{t}
$$

and the Euler equation for the optimal intertemporal allocation of the manager's consumption

$$
\left(c_{t}^{m}\right)^{-\eta_{m}}=\beta E_{t}\left\{\left(c_{t+1}^{m}\right)^{-\eta_{m}}\left(\frac{1+\mu x_{t}}{1+\mu x_{t+1}}\right)\left(\frac{x_{t+1}}{x_{t}}\right) r_{t+1}\right\},
$$

where we define

$$
x_{t} \equiv \partial c_{t}^{m} / \partial d_{t}=\varphi \theta\left(\varphi \delta w_{t} n_{t}+\varphi d_{t}\right)^{\theta-1} \text {. }
$$

These equations, and their log-linearized counterparts, given below, form the basis of the analysis to follow.

\subsection{Approximating the Equilibrium around the Deterministic Steady State}

As we now show, the degree of convexity of the manager's contract has first order effects on the equilibrium dynamics. Denoting the steady state value of a variable with an overhead bar and the log-deviations from that steady state value with a ^, we can characterize the model's dynamics by 
the following log-linearized equilibrium conditions: ${ }^{16}$

$$
\begin{aligned}
\hat{c}_{t}^{m} & =\theta\left(1-A / \bar{c}^{m}\right)\left[\frac{\delta \omega}{\delta \omega+1-\omega} \hat{y}_{t}+\frac{1-\omega}{\delta \omega+1-\omega} \hat{d}_{t}\right], \quad \text { where } \omega \equiv \frac{\bar{w} \bar{n}}{\bar{w} \bar{n}+\bar{d}} \\
(1+\mu \bar{x}) \frac{\bar{d}}{\bar{y}} \hat{d}_{t}^{s} & =\left(\alpha-\mu \bar{x} \frac{\delta \omega}{1-\omega} \frac{\bar{d}}{\bar{y}}\right) \hat{y}_{t}-\Omega \frac{\bar{k}_{\bar{t}}}{\bar{y}} \hat{\imath}_{t} \\
\hat{y}_{t} & =\hat{\lambda}_{t}+\alpha \hat{k}_{t}+(1-\alpha) \hat{n}_{t} \\
\hat{w}_{t} & =\hat{y}_{t}-\hat{n}_{t} \\
\hat{r}_{t} & =(1-\beta(1-\Omega))\left(\hat{y}_{t}-\hat{k}_{t}\right) \\
\eta_{s} \hat{c}_{t}^{s}+\zeta \hat{n}_{t} & =\hat{w}_{t} \\
\hat{k}_{t+1} & =(1-\Omega) \hat{k}_{t}+\Omega \hat{\imath}_{t}
\end{aligned}
$$

and the log-linearized Euler equation for the manager's consumption

$$
\hat{c}_{t}^{m}=E_{t} \hat{c}_{t+1}^{m}-\psi^{-1} E_{t} \hat{r}_{t+1}
$$

where

$$
\psi \equiv \eta_{m}-\frac{\theta-1}{\theta} \frac{1}{\left(1-A / \bar{c}^{m}\right)(1+\mu \bar{x})}
$$

corresponds to the manager's coefficient of relative risk aversion adjusted for features of the incentive contract, such as its degree of convexity $\theta$, and the fraction $A / \bar{c}^{m}$ of the manager's compensation that is fixed $\left(0 \leq A / \bar{c}^{m}<1\right)$. As we will see below, $\psi$ will turn out to be a key coefficient for the model's dynamics.

\subsection{Indeterminacy: Intuition}

To understand how self-fulfilling fluctuations may arise in this economy, it is important to note that in equation (29), the coefficient $\psi^{-1}$ represents the elasticity of intertemporal substitution in the manager's consumption in response to changes in the manager's personal rate of return

\footnotetext{
${ }^{16}$ The steady state in this economy is defined as the solution to the following set of equations: $\bar{c}^{m}=A+$ $(\varphi \delta \bar{w} \bar{n}+\varphi \bar{d})^{\theta} ; \bar{w} \bar{n}=(1-\alpha) \bar{y} ; \bar{y}=\bar{k}^{\alpha} \bar{n}^{1-\alpha} ; \Omega \bar{k}=\bar{\imath} ; \bar{x}=\varphi \theta(\varphi \delta \bar{w} \bar{n}+\varphi \bar{d})^{\theta-1} ; \bar{r}=\alpha \bar{y} / \bar{k}+1-\Omega ; \beta^{-1}=\bar{r} ;$ $\bar{c}^{s}=\bar{w} \bar{n}+\bar{d}$ and $\left(\bar{c}^{s}\right)^{-\eta_{s}} \bar{w}=B \bar{n}^{\zeta}$.
} 
on investment, i.e., the effective rate of return from the manager's point of view. That rate of return does not only represent the additional output generated by another unit of investment in physical capital, but also the additional compensation distributed to the manager as a result of that additional unit of output. As indicated in (30), the degree of convexity of the incentive contract, $\theta$, is a key determinant of the manager's intertemporal elasticity of substitution, and that for $\theta$ sufficiently larger than $1, \psi^{-1}$ may even be negative. As argued below, a negative $\psi$ can imply an indeterminate equilibrium, so that economic fluctuations may result from self-fulfilling manager's expectations.

For comparison purposes, let us first explore the case where $\theta=1$, a linear contract, so that $\psi=\eta_{m}$. For these circumstances equation (29) reduces to the same log-linearized consumption Euler equation as would be obtained for the standard representative agent problem: $\hat{c}_{t}^{m}=E_{t} \hat{c}_{t+1}^{m}{ }_{-}$ $\eta_{m}^{-1} E_{t} \hat{r}_{t+1}$. Here date $t$ consumption responds negatively to increases in the expected rate of return (for given expected future consumption), and the response coefficient is the elasticity of intertemporal substitution. Assume that the manager suddenly expects a higher rate of return on capital next period, $\hat{r}_{t+1}$, than would be justified by fundamentals. In this case $\left(E_{t} \hat{c}_{t+1}^{m}-\hat{c}_{t}^{m}\right)$ must increase or $\hat{c}_{t}^{m}$ must get smaller, which can occur only if the agent saves more and so simultaneously $\hat{c}_{t+1}^{m}$ increases. But with the expectation of the higher return on capital the next period's capital stock, $\hat{k}_{t+1}$, also increases. The increase in the capital stock causes the marginal product of capital to drop (so that $\hat{r}_{t+1}$ declines). As a result, expectations of a higher return on capital cannot be filled and there is no supportable equilibrium indeterminacy.

In the case of a convex compensation function $(\theta>1)$, a given increase in the firm's output generated by an additional unit of physical investment results in a more than proportional increase in the manager's income. Let us consider the manager's contract with convexity sufficiently larger than 1 to guarantee that $\psi$ is negative. In that case, suppose that the manager has the belief (unrelated to fundamentals) that his own personal return will be "high" next period. The perception of a high income next period will lead him - in the interest of consumption smoothing - to consume more today, and thus to reduce his investment today. The lower investment leads to a higher rate of return on capital which confirms the manager's belief of a high personal rate of return.

In general, the larger the convexity of the executive contract, the more likely $\psi^{-1}$ is negative, 
and hence the more likely the manager will increase his consumption and lower investment in the firm in response to his belief of an increase in the rate of return. It follows that the more convex is the executive contract, the more likely the general equilibrium is indeterminate, so that business cycles can be driven by self-fulfilling fluctuations in manager's expectations. In contrast, with low convexity of the manager's contract $(\theta \leq 1)$, the increase in return on capital is smaller from the manager's perspective. In this case, the contract works against the manager's "personal returns expectations" being fulfilled.

The mechanism works similarly to the combination of constant returns to scale at the firm level but increasing returns at the economy-wide level, although in our case, production is generated with constant returns to scale. The appearance of equilibrium indeterminacy when $\psi$ becomes negative relates also to Bilbiie (2008), who obtains an indeterminate equilibrium in a monetary model, when the fraction of households who are excluded from asset markets is sufficiently large. In that case, the economy-wide elasticity of intertemporal substitution in consumption similarly becomes negative. However, in contrast to Bilbiie (2008), our mechanism does not require households to be excluded from asset markets, and, even if we have assumed that mangers do not trade securities, the latter assumption or the measure of managers in the economy $(\mu)$ are not critical for our result.

An inspection of (30) also reveals that the lower the manager's risk aversion, $\eta_{m}$, the more likely $\psi$ is negative and hence equilibrium indeterminacy can arise $\left(\partial \psi / \partial \eta_{m}=1>0\right)$. In the extreme case of a risk-neutral manager $\left(\eta_{m}=0\right)$, any convexity of the incentive contract $(\theta>1)$, no matter how small, implies a negative coefficient $\psi$, and hence can result in an indeterminate equilibrium. Similarly, for any convex contract $(\theta>1)$, the larger the constant salary component of the executive contract, $A$, the more likely $\psi$ is negative, and, again, the more likely equilibrium indeterminacy can arise. By making the manager's compensation less volatile, the higher fixed salary component reduces the magnitude of the incentives part of the contract necessary to generate indeterminacy. Below, we formalize this intuition. 


\subsection{Indeterminacy and Instability in the Case of Fixed Labor Supply: An An- alytical Characterization}

We now determine the regions of the parameter space in which the model dynamics around the deterministic steady state yields (i) a unique bounded equilibrium, (ii) an indeterminate equilibrium so that an infinite number of bounded equilibria are consistent with the model's equations, or (iii) no bounded equilibrium so that the model's dynamics can only result in explosive paths. To derive analytical results, we consider a specification of (2) with a fixed labor supply $(\zeta \rightarrow \infty)$. It can be demonstrated numerically that none the results presented here are affected by this assumption. In particular, the region of determinacy, or indeterminacy/instability is independent of the value of $\zeta$.

After combining the linearized equilibrium conditions (21)-(29), the model's local dynamics can be summarized by the following two equations:

$$
\begin{aligned}
E_{t} \hat{c}_{t+1}^{m} & =\hat{c}_{t}^{m}-A_{12} \hat{k}_{t+1}+\operatorname{exog}_{t} \\
\hat{k}_{t+1} & =B_{21} \hat{c}_{t}^{m}+B_{22} \hat{k}_{t}+\operatorname{exog}_{t}
\end{aligned}
$$

where $\operatorname{exog}_{t}$ denotes exogenous terms that depend on current and on expected future realizations of the productivity shock $\lambda_{t}$, and ${ }^{17}$

$$
\begin{aligned}
& A_{12}=\psi^{-1}(1-\alpha)(1-\beta(1-\Omega)) \\
& B_{21}=-\frac{\omega^{-1}-(1-\delta)}{\theta} \frac{\bar{c}^{m}}{\left(\bar{c}^{m}-A\right)} \frac{(1-\alpha)}{\alpha}\left(\beta^{-1}-1+\Omega\right)(1+\mu \bar{x})<0 \\
& B_{22}=\left(\beta^{-1}-(1-\Omega)\right)(1-\alpha) \delta+(1-\Omega)(1-\alpha)+\alpha \beta^{-1}>0 .
\end{aligned}
$$

Note from (33) that $\operatorname{sign}\left(A_{12}\right)=\operatorname{sign}(\psi)$. Note from (34) that $B_{22}$ is increasing in $\delta$, and, for $\alpha$ sufficiently small and $\beta$ sufficiently close to 1 , there exists a positive threshold

$$
\delta^{*} \equiv 1-\frac{\beta^{-1}-1}{\left(\beta^{-1}-1+\Omega\right)(1-\alpha)}<1
$$

\footnotetext{
${ }^{17}$ Equation (31) is obtained by combining (29) and (26), using (24) to substitute for $\hat{y}_{t}$, and noting from (27) that $\hat{n}_{t}=0$ in the case that $\zeta \rightarrow \infty$. To obtain (32), we first use (23) to express $\hat{\imath}_{t}$ as a function of $\hat{c}_{t}^{m}, \hat{k}_{t}$, and $\lambda_{t}$ exploiting (21) to solve for $\hat{d}_{t}$, and (24) to eliminate $\hat{y}_{t}$, and then combine the resulting expression with (28).
} 
such that ${ }^{18}$

$$
B_{22}<1 \text { if and only if } \delta<\delta^{*} \text {. }
$$

The characterization of the regions of determinacy, indeterminacy and instability of the equilibrium resulting from the dynamic system (31)-(32) can be summarized as follows:

Theorem 3 In the case of a fixed labor supply $(\zeta \rightarrow \infty)$, the linearized model admits:

(i) an indeterminate equilibrium (i.e., a continuum of bounded solutions) if and only if the following conditions are jointly satisfied:

$$
\begin{aligned}
\psi & <0 \\
A_{12} B_{21} & <2\left(B_{22}+1\right) \\
\delta & <\delta^{*}
\end{aligned}
$$

(ii) an unstable equilibrium (i.e., no bounded solutions) if and only if (37) and (38) hold and

$$
\delta>\delta^{*}
$$

(iii) a determinate equilibrium (i.e., a unique bounded solution) if and only if either (37) or (38) or both conditions are violated.

Proof. See Appendix B.

We interpret this theorem in the context of the remarks below.

Remark 1: Indeterminacy or instability (i.e., no bounded solution) arise provided that (37) and (38) hold. Under these conditions, the equilibrium is indeterminate for $\delta$ sufficiently small $\left(\delta<\delta^{*}\right)$ and unstable for $\delta>\delta^{*}$.

Remark 2: When either (37) or (38), or both are violated, then we have a unique bounded equilibrium. So, a sufficient condition for a unique bounded equilibrium is $\psi>0$.

To have some sense of the relevance of these conditions, we calibrate the model as follows:

\footnotetext{
${ }^{18}$ Note in particular that when $\delta=1, B_{22}=\beta^{-1}>1$.
} 
$\beta=0.99, \alpha=0.36, \Omega=0.025$. With these parameter values, the implied critical value $\delta^{*}=0.55$. In addition, we assume that shareholder-workers have log utility in consumption, so that $\eta_{s}=1$, and that the share of wage income, $\omega$, is 0.9 . Figure 1 represents the regions of determinacy, indeterminacy and instability for various values of $\eta_{m}$ and the parameters characterizing the incentive contract, i.e., $\theta, \delta$ and $A / \bar{c}^{m}$. The boundary for the region of determinacy in the $\left(A / \bar{c}^{m}, \theta\right)$ space remains the same for the different values of $\delta$ represented in the two columns of Figure ??. With $\delta$ sufficiently low, the model exhibits local indeterminacy when the convexity of the contract $\theta$ rises. For $\delta=1$, even a mildly convex managerial contract $(\theta>1)$ can lead to an indeterminate or explosive general equilibrium in the economy.

To get some intuition for this result, suppose that we start at the steady state and that there is no fundamental shock, i.e., $\lambda_{t}=0$ for all $t$. We provide intuition based on conditions (37) and (39), avoiding a discussion of condition (38) which is likely to be satisfied.

Case 1: determinacy $(\psi>0$, i.e. $\theta<1)$

Suppose agents observe an unexpected sunspot $\nu_{0}$ shock at date 0 , which leads managers to consume more than in steady state $\left(\hat{c}_{0}^{m}>0\right)$. Since the initial capital stock is fixed at $\bar{k}$, the linearized equation for the capital stock, (32), implies that the capital stock in the next period will need to decrease $\left(\hat{k}_{1}<0\right)$ because managers now consume more and invest less in physical capital. According to (31), high consumption by managers at date 0 and lower capital stock at date 1 , leads to even higher managerial consumption in period 1 if $\psi>0$ because

$$
E_{t} \hat{c}_{1}^{m}=\hat{c}_{0}^{m}-\psi^{-1}(1-\alpha)(1-\beta(1-\Omega)) \hat{k}_{1}
$$

This, in turn, causes a further drop in the capital stock and an increase in consumption by managers in period 2: $E_{t} \hat{c}_{2}^{m}>E_{t} \hat{c}_{1}^{m}>c_{0}$, and so on. Such path violates the transversality condition because in the case of $\psi>0$ the presence of a sunspot is inconsistent with a bounded equilibrium. Therefore, if a bounded equilibrium exists, it must be unique.

\section{Case 2: indeterminacy $\left(\psi<0\right.$ and $\left.\delta<\delta^{*}\right)$}

Suppose instead that $\psi<0$ and agents again observe an unexpected sunspot $\nu_{0}$ at date 0 , which 
leads managers to consume more at that time. Again, since the initial capital stock is fixed at its steady state value, equation (32) implies that the capital stock must decrease because a higher consumption by the executives is generated by a higher income to the executives, which means that less is available for investment in physical capital.

But with $\psi<0$ equation (41) implies that the increase in managerial consumption at date 0 combined with the lower capital stock at date 1, leads the manager to consume less in period 1 than in period 0. Hence the consumption of the executive reverts back to the initial steady state and by equation (32) so does capital stock, as $\hat{k}_{2}>\hat{k}_{1}$. This process leads to a stationary path for the manager's consumption and for the capital stock. If $\psi<0$, sunspot shocks are therefore consistent with a bounded equilibrium and there exist an infinite number of such bounded equilibria satisfying the model's restrictions, including some equilibria with arbitrary large fluctuations, as $\nu_{t}$ itself can be arbitrarily large.

\section{Case 3: instability $\left(\psi<0\right.$ and $\left.\delta>\delta^{*}\right)$}

Suppose again that $\psi<0$, and that $\delta$ exceeds its critical value so that $A_{12}<0$ and $B_{22}>1$. Consider a productivity or sunspot shock at date 0 , which leads managers to consume more and invest less. Again, the capital stock at date 1 must fall below its steady state value. According to equation (41), if $\psi<0$ the manager's consumption in period 1 must be lower relative to his consumption in period 0. According to equation (32), a decrease in the manager's consumption tends to bring the future capital closer to its steady state value, but the date 1 deviation of the capital stock is amplified if $B_{22}>1$. It follows that the capital stock embarks on an explosive (or implosive) trajectory, converging to 0 in our example. This, in turn, results in an explosive evolution of the manager's consumption. Hence the model admits no bounded solution.

\subsection{Indeterminacy and Instability for General Labor Supply}

We use a numerical solution to show that the regions of determinacy remain the same when the labor supply is elastic although the split between indeterminacy and instability regions depends on the value of the Frisch elasticity of labor supply $\zeta^{-1}$ as well as the fraction $\delta$ of executive compensation related to aggregate labor income. Figures ?? and ?? show determinacy, indeterminacy, and 
instability regions in the $\left(A / \bar{c}^{m}, \theta\right)$ space, for different values of $\zeta$. In Figure ??, we set $\zeta^{-1}=0.5$ to match the Frisch elasticity of labor supply often found in microeconomic studies, while in Figure ??, $\zeta^{-1} \rightarrow \infty$ consistently with the labor supply found in Hansen (1985). Once again, with sufficiently low $\delta$, the convex executive compensation contract can easily generate an indeterminate equilibrium. Instead when $\delta$ is sufficiently large, the convex contract results in an explosive equilibrium dynamics.

\subsection{General Equilibrium and Optimal Incentive Contracts}

The discussions in Sections 4.1-4.5 refer to the general family of incentive contracts of the form (17)-(18), and argue that the general equilibrium can be indeterminate or explosive if the contract convexity, $\theta$, is excessive or if the fix payment, $A$, is sufficiently large. A natural question is how close an optimal contract would be to these regions of equilibrium indeterminacy or instability. As we now show, while the optimal incentive contract would result in a unique stable equilibrium, slightly more generous incentive contracts could easily result in undesirable outcomes. This will be apparent from the interpretation of Figure 4.

By Theorem 1, contract optimalilty requires that $A=0$ and $\theta=\frac{1-\eta_{s}}{1-\eta_{m}}$. In Figure 4 , the two asymptotic-to-the-vertical and boldfaced curves capture this latter relationship in the $\left(\eta_{m}, \theta\right)$ plane, for two different choices of $\eta_{s}$ on either side of $1 .^{19}$ In the special case that $\eta_{m}=\eta_{s} \neq 1$, the convexity of the optimal contract is $\theta=1$. Instead, if $\eta_{m}=\eta_{s}=1$, so that both agents have $\log$ preferences, Appendix A informs us that the optimal contract convexity can be any value $\theta \geq 0$, as represented by the vertical line. Conditional on shareholder risk aversion, $\eta_{s}$, these lines effectively determine the optimal contract convexity given the manager's coefficient of relative risk aversion, $\eta_{m}$

In contrast, the shaded regions in Figure 4 present the parameter combinations for which indeterminacy or instability will arise. Essentially, these are parameter configurations which satisfy $\psi<0$, where $\psi$ is again defined in (30). In particular, the dark-shaded region, defined by $\left\{\left(\eta_{m}, \theta\right): \psi \equiv \eta_{m}-\frac{\theta-1}{\theta} \frac{1}{\left(1-A / \bar{c}^{m}\right)(1+\mu \bar{x})}<0 ; A=0, \mu=0\right\}$ is the region of indeterminacy or insta-

\footnotetext{
${ }^{19}$ More specifically, the set-theoretic representations of the left and right boldfaced curves are respectively: $\left\{\left(\eta_{m}, \theta\right): \theta=\frac{1-\eta_{s}}{1-\eta_{m}} ; \eta_{s}=0.5\right\}$ and $\left\{\left(\eta_{m}, \theta\right): \theta=\frac{1-\eta_{s}}{1-\eta_{m}} ; \eta_{s}=2\right\}$.
} 
bility in the case that the fixed payment is set at the value of the optimal contract, $A=0$. As mentioned above, indeterminacy or instability may arise provided that the contract is sufficiently convex and the manager's risk aversion is sufficiently low. Notice that this region does not intersect with either of the boldfaced curve representing the optimal contracts, nor would it for any other choice of $\eta_{s}$. While the optimal contract does not per se lead to equilibrium indeterminacy or instability, a slightly more generous compensation in terms of higher contract convexity would could easily result in such bad outcomes. This could arise, for instance, in the case that shareholder-workers, who determine the contract forms and parameters, know their own coefficient of relative risk aversion but mistakenly over-estimate the manager's true degree of risk aversion. For example, suppose that the true $\eta_{s}$ and $\eta_{m}$ satisfy $\eta_{s}=\eta_{m}=0.5$, so that the optimal contract parameters are $A=0$ and $\theta=1$. If the shareholders counterfactually estimate $\eta_{m}=0.8$, then they will choose contract parameters $A=0$ and $\theta=\frac{1-\eta_{s}}{1-\eta_{m}}=2.5$. Relative to the true $\eta_{m}$ which guides the manager's actions, this choice of $\theta$ leads to indeterminacy or explosive equilibria as $\psi=\eta_{m}-\frac{\theta-1}{\theta}=0.5-\frac{1.5}{2.5}<0$.

The larger shaded region (comprising the dark and light gray regions) similarly represents the region of indeterminacy or instability, but assuming a positive fraction of the manager's compensation in the form of a fixed payment. Specifically, it assumes $A / \bar{c}^{m}=0.5$. As Figure 4 makes clear, for any $\eta_{m}$, the minimal magnitude of $\theta$ necessary for indeterminacy is strictly less than in the $A / \bar{c}^{m}=0$ case. Note also that for a wide range of manager risk aversion, $\eta_{m}$, the choice of convexity $\theta$ in the optimal contract leads to indeterminacy or instability when $A / \bar{c}^{m}=0.5$. A larger positive fixed payment thus allows indeterminacy to arise for a much larger set of parameter configurations. We are also reminded that the presence or absence of indeterminacy is related only to the manager and the terms of his contract: nowhere does $\eta_{s}$ enter into the definition of the region of indeterminacy. This observation follows from the fact that the manager alone determines the firm's investment decision in the delegated management economy.

In light of these observations, we find intriguing the recent decision of some financial institutions to alter the compensation structure for their managing directors by increasing the share of fixed compensation while retaining some of the contract convexity. For instance on May 23, 2009, the Wall-Street Journal reported: "Morgan Stanley Boosts Salaries as Its Bonuses Are Limited [...] 
Under the changes, managing directors will see about $25 \%$ to $30 \%$ of their overall compensation come from their base salary, up from about $15 \%$ to $20 \%$." Within the context of our model, and without a corresponding reduction in the convexity of the bonus portion of their compensation, such actions increase the likelihood of sunspot equilibria, if other firms act similarly.

\section{Computing Equilibria}

Our numerical work is guided by three questions: (1) Is it possible to generate a business cycle with the observed properties on the basis of sunspot shocks alone? Less extreme versions of this query are the following: (2) In conjunction with a standard technology shock, does the addition of a sunspot shock enhance the explanatory power of the model in the context, e.g., of labor market volatility? Lastly and minimally, (3) we may ask if the sunspot shock is, at least, fully harmonious with a productivity shock in the sense of the addition of the former not compromising the overall model's performance. If this is the case it becomes difficult to separate out the sources of business cycle fluctuations. For those skeptical of the notion of a productivity disturbance as an economic driver, such a result diminishes their significance, at least in our neoclassical context. It has the less attractive implication, however, of suggesting that future macroeconomic volatility may not be forecastable since it may in part be determined by pure belief shocks.

\section{$5.1 \quad$ Numerical Strategy}

The linearized rational expectations model presented in Section 4, can be rewritten in the canonical form:

$$
\Gamma_{0}(\vartheta) s_{t}=\Gamma_{1}(\vartheta) s_{t-1}+\Psi(\vartheta) \varepsilon_{t}+\Pi(\vartheta) \tau_{t}
$$

where the model parameters are collected in the vector $\vartheta=\left[\beta, \eta_{s}, B, \eta_{m}, \mu, \theta, \varphi, \delta, A, \alpha, \Omega, \rho, \sigma\right]$, with $\rho$ and $\sigma$ denoting, respectively, the persistence and the standard deviation of the exogenous shock, and $s_{t}$ representing the vector of the model's endogenous variables:

$$
s_{t}=\left[\hat{c}_{t}^{s}, \hat{c}_{t}^{m}, \hat{k}_{t}, \hat{n}_{t}, \hat{\imath}_{t}, \hat{d}_{t}, \hat{y}_{t}, \hat{w}_{t}, \lambda_{t}, E_{t} \hat{n}_{t+1}, E_{t} \hat{c}_{t+1}^{m}, E_{t} \hat{d}_{t+1}, E_{t} \lambda_{t+1}\right]^{\prime}
$$


Finally, $\tau_{t}$ denotes the vector of rational expectations forecast errors:

$$
\tau_{t}=\left[\left(\hat{n}_{t}-E_{t-1} \hat{n}_{t}\right),\left(\hat{c}_{t}^{m}-E_{t-1} \hat{c}_{t}^{m}\right),\left(\hat{d}_{t}-E_{t-1} \hat{d}_{t}\right),\left(\lambda_{t}-E_{t-1} \lambda_{t}\right)\right]^{\prime}
$$

The model is solved using the solution algorithm developed by Sims (2000) as adapted to sunspot equilibria by Lubik and Schorfheide (2003). In the case of indeterminacy, in addition to the fundamental technology shock, the manager observes an exogenous sunspot shock, $\nu_{t}$, which influences dynamics of the key macroeconomic variables. Consistency with rational expectations requires that the sunspot is i.i.d. with $E_{t-1} \nu_{t}=0$.

Because of the linear structure of the model, the forecast errors for the next period labor, level of technology, dividend, and manager's consumption can be expressed as function of two sources of uncertainty: the technology shock and the sunspot

$$
\tau_{t}=\Phi_{1} \varepsilon_{t}+\Phi_{2} \nu_{t}
$$

where $\Phi_{1}$ and $\Phi_{2}$ have dimension $4 \times 1$. The solution algorithm of Sims (2000) explicitly constructs a mapping from shocks to the expectation errors in (42). As shown above, when $\delta$ is sufficiently small, our model has at least one stable solution. If $\Phi_{1}$ is uniquely determined by the parameters $\vartheta$ and $\Phi_{2}=0$, the model has a unique solution. This is the case of determinacy in which the propagation mechanism of the technology shocks is uniquely determined. Thus, neither do sunspots affect equilibrium allocations nor do they induce fluctuations. If $\Phi_{1}$ is not uniquely determined by the parameters $\vartheta$ and $\Phi_{2}$ is different from zero, the equilibrium is indeterminate. In this case, sunspot shocks can be interpreted as shocks to endogenous forecast errors. Detailed technical conditions for indeterminacy are developed in Lubik and Schorfheide (2003). In our model, it is the subset of $\vartheta$ related to the manager's compensation and risk aversion that is critical for indeterminacy; this is given by $\vartheta_{\nu}=\left[\eta_{m}, \theta, \delta, A\right]$. 


\section{$5.2 \quad$ Numerical Results}

We solve for the model's optimal policy functions in the manner described above, and generate artificial time series accordingly. These series are then detrended using the Hodrick-Prescott filter, and the standard business cycle statistics are computed from their detrended components. In all cases the parameters $\alpha, \beta, \Omega$ are calibrated as in Section $4(\alpha=0.36, \Omega=0.025, \beta=0.99)$. We fix the shareholder-worker's coefficient of relative risk aversion at $\eta_{s}=1$ and the inverse of the Frisch elasticity of labor supply at $\zeta=0$. Following the business cycle literature, we choose $B$ (2.85) so that the steady state value of $n$ is $1 / 3{ }^{20}$ The delegated manager's utility function is of the form (16), with $0<\eta_{m}<1$. His measure is $\mu=0.20$.

We focus exclusively on contracts of the form (17)-(18) with $\varphi=0.01$. The technology shock process is of the form $\lambda_{t}=\rho \lambda_{t-1}+\tilde{\varepsilon}_{t}$ with $\rho=0.95$ and with $\sigma_{\varepsilon}$ chosen so that $\sigma_{y}$ matches the data. The i.i.d. sunspot shock, if present, is distributed $N\left(0, \sigma_{\nu}\right)$, with $\sigma_{\nu}$ a choice variable.

Averages of statistical quantities computed repeatedly for 500 sample paths each of 200 periods length are presented. Summarizing model performance in this way is customary in the business cycle literature. It does, however, tend to mask the sort of extreme behavior we might expect to be associated with sunspot equilibria.

Table 1 considers a pair of benchmark cases. In panel B, both technology and sunspot shocks are present, with the indicated volatilities, $\sigma_{\varepsilon}=1.04 \%$, and $\sigma_{\nu}=4.81 \%$. In Panel $\mathrm{C}$ only the i.i.d. sunspot shock is present (albeit with a higher volatility), while in Panel A, U.S. data is provided where available. Panel B easily respects the most basic stylized facts of the business cycle: investment is more volatile than output which is in turn more volatile than shareholder (and aggregate) consumption. Hours are somewhat too smooth, however.

Being a convex function of the dividend, which is itself a highly variable residual series, managerial consumption volatility dramatically exceeds that of the shareholder-workers. Comparing the volatilities presented in Panel A with U.S. data, it would appear that sunspot shocks, when introduced into this production model setting, are largely consistent with the stylized business cycle facts (question 1). For all the major aggregates the same can be said of the cross-correlations with output. In fact, the case with indeterminacy arguably does a better job of replicating the data than

\footnotetext{
${ }^{20}$ With this comparison, the model is directly analogous to the representative agent construct of Hansen (1985).
} 
does the seminal paradigm of Hansen (1985) (Panel D). in particular, consumption volatility much more closely matches the data. The negative correlation of managerial consumption with output simply reflects the like correlation of its dividend base.

Sunspot shocks alone (Panel B) give rise to a number of data inconsistencies. First hours and investment are excessively volatile. Note that the volatility of the sunspot shock must exactly double in order to compensate for the absence of technological uncertainty (Panel B vs. Panel A), if the required volatility of output is to be maintained. This fact is not entirely surprising since sunspot shocks do not affect output directly, and thus must induce large responses in hours and investment in order to replicate $\sigma_{y}$ at the empirically observed $\sigma_{y}=1.81 \%$. As a result, $\sigma_{i}$ and $\sigma_{n}$ are high relative to their empirical counterparts. For the parameterization of Table 1, $\zeta=0.10$, dividends give rise to most of the variation in managerial compensation and these are countercyclical. As a result, managerial consumption is countercyclical as well. Being a residual after the wage bill and investment, dividend - and thus managerial consumption - are also highly volatile.

The second major inconsistency is reflected in the negative correlation of shareholder-worker consumption with output. By implication, total consumption is negatively correlated with output as well. Sunspot equilibria, per se, seem to have manifestations that violate the notion of consumption as a normal good, at least in this case. Recall that a sunspot shock is essentially a rate of return on capital stock, and that it induces very large procyclical responses in investment without output being itself simultaneously increased. In equilibrium, consumption must be countercyclical. Note that for both these cases contract convexity is a modest $\theta=2$.

Table 2 explores the consequences of greater contract convexity, a larger salary component, and higher managerial risk aversion in the context of the Benchmark case of Table 1, Panel A. The Table 2 cases illustrate indeterminate equilibria that all provide reasonable replications of the basic business cycle stylized facts. It reflects the fact that indeterminacy is robust to a wide class of contract parameters and risk aversion levels for the manager. In Panel B (higher contract convexity with $\theta=3$ ), the volatility of hours and investment is lower than in the benchmark case (Panel A). Higher contract convexity allows the manager to take advantage of favorable shock without altering hours or investment as in the case of lower convexity. But by and large, the degree of contract 
convexity has only a modest influence on the basic volatility and correlation structure of the various series.

Panel C in Table 2 explores the consequences of altering the level of the salary component. For the underlying parameters of $\eta_{m}=0.25$ and $\theta=2$, sensitivity analysis reveals that a minimum value of salary component share in the manager's compensation $A / \bar{c}^{m}=0.32$ appears to be necessary for indeterminate equilibria to arise.

Increasing the magnitude of the fixed salary component appears to slightly increase the overall volatility in the economy once indeterminate equilibria are achieved. The effect is more pronounced in case of hours and investment volatility. Increasing the weight of the fixed salary in the overall compensation package of the manager makes him effectively more risk tolerant and more willing to alter production plans in response to shocks. While emphasizing the importance of the salary component, this latter observation amplifies the essential harmony of sunspot and technology shocks in promoting superior model performance.

Finally, Panel D in Table 2 concerns the consequences of enhanced managerial risk aversion. Sensitivity analysis shows that the model economy exhibits local indeterminacy if the manager's risk aversion coefficient does not exceed 0.359 with other parameters held at their Benchmark values. As is evident, the influence of the increase in managerial risk aversion is very modest provided the equilibria are indeterminate. Indeed, for Panel D, not only are the stylized business cycle facts quite well replicated but the results seem relatively unaffected by the degree of managerial risk aversion (i.e., provided $\eta_{m}<0.359$ ). In none of these cases furthermore (as well as all previous cases) is managerial consumption volatility particularly excessive, ranging only to roughly three times that of the average shareholder-worker.

With regard to the three questions posed at the start of this section, the preceding cases inform us along a number of dimensions. First, within the realm of the simple construct we provide, it does not appear that convex-contract-induced sunspot equilibria, alone, can replicate the stylized facts of the business cycle. Shareholder consumption in these cases is negatively correlated with output. Such is our tentative response to the first question posed. With regard to the third question, not only the benchmark case with technology and sunspot shocks (Table 1, Panel B) but also many of the other cases suggest that these sources of uncertainty are fully compatible with 
one another, at least for this model framework. It suggests that one source of uncertainty can effectively be traded off against the other (with regard to the relative magnitudes of $\sigma_{\nu}$ and $\sigma_{\varepsilon}$ ), a direct consequence being that a large increase in future sunspot volatility would not be inconsistent with past business cycle history as it is currently understood and measured. With regard to our second question, standard business cycle models (e.g., Hansen (1985)) have difficulty replicating the relative volatility of hours. The addition of sunspot equilibria appears to resolve this shortcoming.

\section{Conclusion}

The message of this paper is clear and direct: low risk aversion CEOs, when confronted with compensation contracts which are mildly convex to the firm's stock price or free cash flow may well find it in their self-interest to adopt investment policies that lead to equilibrium indeterminacy or instability. As a result, the time path of the economy's macroeconomic aggregates, as well as the executives' compensation, at least with respect to their volatility, may bear little association to fundamentals. In this sense, convex CEO compensation contracts may substitute for technological increasing returns, a typical requirement of the earlier indeterminacy literature. Within a standard dynamic macroeconomic setup, these results appear to hold for a wide class of model parameters, at least for the compensation contracts studied here.

These results suggest that the early twenty-first century explosion in the incentive compensation among financial firms may have unforeseen consequences. We are only now beginning to see what these consequences are. 


\section{A Appendix A: Proof of Theorem 1}

We present here only an overview of the result stated in Theorem 1 . The formal proof is detailed in Danthine and Donaldson (2008 b). We consider the economy presented in Section 2, with a continuum of shareholder-worker-investors of measure one and a measure $\mu=0$ of managers. We first describe the Pareto optimal competitive equilibrium conditions in the case that shareholderworkers run the firm themselves so as to maximize its share price. We then demonstrate that the delegated management economy where the manager is given a contract of the form described in Theorem 1 yields the same equilibrium.

In the Pareto optimal competitive economy, the necessary first-order condition for optimal employment and investment can be expressed respectively as follows:

$$
\begin{aligned}
w_{t} & =(1-\alpha) k_{t}^{\alpha} n_{t}^{-\alpha} e^{\lambda_{t}} \\
\left(y_{t}-i_{t}\right)^{-\eta_{s}} & =\beta \int\left(y_{t+1}-i_{t+1}\right)^{-\eta_{s}}\left[\alpha k_{t+1}^{\alpha-1} n_{t+1}^{1-\alpha} e^{\lambda_{t+1}}+1-\Omega\right] d F(),
\end{aligned}
$$

where we recognize the fact that in equilibrium the representative agent's consumption satisfies $c_{t}=y_{t}-i_{t}$.

Instead, in the delegated management economy described in Section 2, the necessary firstorder condition for optimal employment and investment are respectively (14) and (15). With a compensation contract of the form (17)-(18), and recognizing that dividends are given by $d_{t}=$ $y_{t}-w_{t} n_{t}^{f}-i_{t}$ when $\mu=0$, we can express the manager's performance as $h_{t}()=\varphi\left(\delta w_{t} n_{t}+\right.$ $\left.k_{t}^{\alpha}\left(n_{t}^{f}\right)^{1-\alpha} e^{\lambda_{t}}-w_{t} n_{t}^{f}-i_{t}\right)$ and his consumption as $c_{t}^{m}=g_{1}^{m}\left(h_{t}()\right)=A+\left(h_{t}()\right)^{\theta}$. The condition for optimal employment (14) thus reduces to

$$
\left(c_{t}^{m}\right)^{-\eta_{m}} \theta\left(h_{t}\right)^{\theta-1}\left((1-\alpha) k_{t}^{\alpha}\left(n_{t}^{f}\right)^{-\alpha} e^{\lambda_{t}}-w_{t}\right)=0 .
$$

Note that in equilibrium, the firm's optimal choice of employment $n_{t}^{f}=n_{t}$ so that the first-order condition (45) reduces to (43) for any contract convexity $\theta>0$.

The condition for optimal investment (15) similarly reduces to

$$
\left(c_{t}^{m}\right)^{-\eta_{m}} \theta\left(h_{t}\right)^{\theta-1} \varphi=\beta \int\left(c_{t+1}^{m}\right)^{-\eta_{m}} \theta\left(h_{t+1}\right)^{\theta-1}\left[\varphi \alpha k_{t+1}^{\alpha-1}\left(n_{t+1}^{f}\right)^{1-\alpha} e^{\lambda_{t+1}}-(-\varphi)(1-\Omega)\right] d H(),
$$

or equivalently, if $\varphi>0$,

$$
\left(A+h_{t}^{\theta}\right)^{-\eta_{m}}\left(h_{t}\right)^{\theta-1}=\beta \int\left(A+h_{t+1}^{\theta}\right)^{-\eta_{m}}\left(h_{t+1}\right)^{\theta-1}\left[\alpha k_{t+1}^{\alpha-1}\left(n_{t+1}^{f}\right)^{1-\alpha} e^{\lambda_{t+1}}+1-\Omega\right] d H() .
$$

Setting the fixed payment $A=0$, noting again that $n_{t}^{f}=n_{t}$ in equilibrium, and replacing $h_{t}$ with $\varphi\left((\delta-1) w_{t} n_{t}+y_{t}-i_{t}\right)$, we can rewrite this condition as

$$
\begin{aligned}
\left(\varphi\left((\delta-1) w_{t} n_{t}+y_{t}-i_{t}\right)\right)^{\theta\left(1-\eta_{m}\right)-1}= & \beta \int\left(\varphi\left((\delta-1) w_{t+1} n_{t+1}+y_{t+1}-i_{t+1}\right)\right)^{\theta\left(1-\eta_{m}\right)-1} \\
& \times\left[\alpha k_{t+1}^{\alpha-1} n_{t+1}^{1-\alpha} e^{\lambda_{t+1}}+1-\Omega\right] d H() .
\end{aligned}
$$


The first-order conditions for optimal employment and investment decisions in the delegated management economy (45) and (46) are thus identical to the ones in the Pareto optimal competitive economy (43) and (44) if and only if $A=0, \varphi>0, \delta=1$, and $\theta\left(1-\eta_{m}\right)-1=-\eta_{s}$. If $\eta_{m} \neq 1$ and $\eta_{s} \neq 1$, the latter condition is satisfied when the convexity parameter is given by

$$
\theta=\frac{1-\eta_{s}}{1-\eta_{m}}
$$

Instead, if $\eta_{m}=\eta_{s}=1$ (so that the manager and the shareholder-worker have both log preferences), then any convexity parameter $\theta>0$ is optimal.

\section{B Appendix B: Proof of Theorem 3}

To characterize the regions of determinacy, indeterminacy and instability, we rewrite the dynamic equations (31)-(32) in matrix form:

$$
A\left[\begin{array}{c}
E_{t} \hat{c}_{t+1}^{m} \\
\hat{k}_{t+1}
\end{array}\right]=B\left[\begin{array}{c}
\hat{c}_{t}^{m} \\
\hat{k}_{t}
\end{array}\right]+C \lambda_{t}
$$

where

$$
A \equiv\left[\begin{array}{cc}
1 & A_{12} \\
0 & 1
\end{array}\right], \quad B \equiv\left[\begin{array}{cc}
1 & 0 \\
B_{21} & B_{22}
\end{array}\right]
$$

and

$$
\begin{aligned}
A_{12} & =\psi^{-1}(1-\alpha)(1-\beta(1-\Omega)) \\
B_{21} & =-\frac{\omega^{-1}-(1-\delta)}{\theta} \frac{\bar{c}^{m}}{\left(\bar{c}^{m}-A\right)} \frac{(1-\alpha)}{\alpha}\left(\beta^{-1}-1+\Omega\right)(1+\mu \bar{x})<0 \\
B_{22} & =(1-\Omega)(1-\alpha)(1-\delta)+\beta^{-1}(\alpha+\delta(1-\alpha)) \\
& =\left(\beta^{-1}-(1-\Omega)\right)(1-\alpha) \delta+(1-\Omega)(1-\alpha)+\alpha \beta^{-1}>0 .
\end{aligned}
$$

Note that $\operatorname{sign}\left(A_{12}\right)=\operatorname{sign}(\psi)$, and that $B_{22}$ is increasing in $\delta$. For $\alpha$ sufficiently small and $\beta$ sufficiently close to 1 , when $\delta=0$, we have

$$
0<B_{22}=(1-\Omega)(1-\alpha)+\alpha \beta^{-1}<1 .
$$

If $\delta=1$, then $B_{22}=\beta^{-1}>1$.

Given that $\hat{k}_{t}$ is a predetermined variable and $\hat{c}_{t}^{m}$ is a nonpredetermined variable, the system admits a single bounded solution if and only if the eigenvalues $\phi_{1}$ and $\phi_{2}$ of the matrix $M \equiv A^{-1} B$ satisfy

$$
0 \leq\left|\phi_{1}\right|<1<\left|\phi_{2}\right|
$$

The equilibrium is indeterminate if

$$
0 \leq\left|\phi_{1}\right|<1 \text { and } 0 \leq\left|\phi_{2}\right|<1
$$

There exists no bounded solution (and so there exist only explosive solutions) if

$$
1<\left|\phi_{1}\right| \text { and } 1<\left|\phi_{2}\right|
$$


It will be useful to appeal to the following proposition:

Proposition 4 (Proposition C1 of Woodford (2003, p. 670)). Both eigenvalues of a $2 \times 2$ matrix $N$ lie outside the unit circle if and only if:

either (Case I):

$$
\begin{aligned}
\operatorname{det}(N) & >1 \\
\operatorname{det}(N)-\operatorname{tr}(N)+1 & >0 \\
\operatorname{det}(N)+\operatorname{tr}(N)+1 & >0
\end{aligned}
$$

or (Case II):

$$
\begin{aligned}
& \operatorname{det}(N)-\operatorname{tr}(N)+1<0 \\
& \operatorname{det}(N)+\operatorname{tr}(N)+1<0 .
\end{aligned}
$$

\section{B.1 Indeterminacy}

Note that the system has an indeterminate equilibrium if and only if $1<\left|1 / \phi_{1}\right|$ and $1<\left|1 / \phi_{2}\right|$, or equivalently if both eigenvalues of

$$
M^{-1}=\left[\begin{array}{cc}
1 & A_{12} \\
-\frac{B_{21}}{B_{22}} & \frac{1}{B_{22}}\left(1-A_{12} B_{21}\right)
\end{array}\right]
$$

lie outside the unit circle. Note that

$$
\begin{aligned}
\operatorname{det}\left(M^{-1}\right) & =\frac{1}{B_{22}} \\
\operatorname{tr}\left(M^{-1}\right) & =1+\frac{1}{B_{22}}\left(1-A_{12} B_{21}\right)
\end{aligned}
$$

and

$$
\begin{aligned}
\operatorname{det}\left(M^{-1}\right)-\operatorname{tr}\left(M^{-1}\right)+1 & =\frac{1}{B_{22}}-\left(1+\frac{1}{B_{22}}\left(1-A_{12} B_{21}\right)\right)+1=A_{12} \frac{B_{21}}{B_{22}} \\
\operatorname{det}\left(M^{-1}\right)+\operatorname{tr}\left(M^{-1}\right)+1 & =\frac{1}{B_{22}}+\left(1+\frac{1}{B_{22}}\left(1-A_{12} B_{21}\right)\right)+1=2\left(\frac{B_{22}+1}{B_{22}}\right)-A_{12} \frac{B_{21}}{B_{22}} .
\end{aligned}
$$

First suppose that $\operatorname{det}\left(M^{-1}\right)-\operatorname{tr}\left(M^{-1}\right)+1=A_{12} \frac{B_{21}}{B_{22}}<0$. Since $B_{22}>0$, we must have $\operatorname{det}\left(M^{-1}\right)+\operatorname{tr}\left(M^{-1}\right)+1=2\left(\frac{B_{22}+1}{B_{22}}\right)-A_{12} \frac{B_{21}}{B_{22}}>0$. So we cannot simultaneously satisfy both conditions (50)-(51) of Case II.

We thus have an indeterminate equilibrium if and only if all three conditions (47)-(49) of Case 
I are satisfied, i.e., if and only if

$$
\begin{aligned}
0 & <B_{22}<1 \\
A_{12} \frac{B_{21}}{B_{22}} & >0 \\
2\left(\frac{B_{22}+1}{B_{22}}\right)-A_{12} \frac{B_{21}}{B_{22}} & >0 .
\end{aligned}
$$

The first condition is satisfied for $\delta$ sufficiently small

$$
\left(\beta^{-1}-(1-\Omega)\right)(1-\alpha) \delta+(1-\Omega)(1-\alpha)+\alpha \beta^{-1}<1
$$

or equivalently

$$
\delta<\delta^{*} \equiv \frac{1-(1-\Omega)(1-\alpha)-\alpha \beta^{-1}}{\left(\beta^{-1}-(1-\Omega)\right)(1-\alpha)} .
$$

Given $B_{22}>0$ and $B_{21}<0$, the second condition is satisfied if and only if $A_{12}<0$, or equivalently if and only if

$$
\psi<0
$$

The third condition is in turn satisfied if and only if

$$
A_{12} B_{21}<2\left(B_{22}+1\right)
$$

To summarize, the model admits an indeterminate equilibrium if and only if (52)-(54) are jointly satisfied.

\section{B.2 Instability}

The system admits no bounded solution if and only if both eigenvalues of $M$ lie outside the unit circle. Note that

$$
\begin{aligned}
\operatorname{det}(M) & =B_{22} \\
\operatorname{tr}(M) & =1+B_{22}-A_{12} B_{21}
\end{aligned}
$$

and

$$
\begin{aligned}
\operatorname{det}(M)-\operatorname{tr}(M)+1 & =B_{22}-\left(1+B_{22}-A_{12} B_{21}\right)+1=A_{12} B_{21} \\
\operatorname{det}(M)+\operatorname{tr}(M)+1 & =B_{22}+\left(1+B_{22}-A_{12} B_{21}\right)+1=2\left(B_{22}+1\right)-A_{12} B_{21}
\end{aligned}
$$

First suppose that $\operatorname{det}(M)-\operatorname{tr}(M)+1=A_{12} B_{21}<0$. Since $B_{22}>0$, we must have $\operatorname{det}(M)+$ $\operatorname{tr}(M)+1=2\left(B_{22}+1\right)-A_{12} B_{21}>0$. So we cannot simultaneously satisfy both conditions (50)(51) of Case II. Thus we have explosive solutions if and only if all three conditions (47)-(49) of Case I are satisfied, that is:

$$
\begin{aligned}
1 & <B_{22} \\
A_{12} B_{21} & >0 \\
2\left(B_{22}+1\right)-A_{12} B_{21} & >0 .
\end{aligned}
$$


The first condition is satisfied for $\delta$ sufficiently large

$$
\delta>\delta^{*} \text {. }
$$

Given $B_{21}<0$, the second condition is satisfied if and only if $A_{12}<0$, or equivalently if and only if (53) holds. The third condition is in turn satisfied if and only if (54) holds.

To summarize, the model admits no bounded solution if and only if (53) and (54) as well as (55) are jointly satisfied. 


\section{References}

[1] Basu, Susanto and John Fernald, 1997, "Returns to Scale in U.S. Production: Estimates and Implications," Journal of Political Economy, 105, 249-283.

[2] Benhabib, Jess and Roger E. Farmer, 1996, "Indeterminacy and Sector Specific Externalities," Journal of Monetary Economics, 37, 397-419.

[3] Benhabib, Jess, Qinglai Meng and Kazuo Nishimura, 2000, "Indeterminacy under Constant Returns to Scale in Multisector Economies," Econometrica, 68(6), 1541-1548.

[4] Bilbiie, Florin O., 2008, "Limited Asset Markets Participation, Monetary Policy and (Inverted) Aggregate Demand Logic," Journal of Economic Theory, 140(1), 162-196.

[5] Bolton, Patrick and Mathias Dewatripont, 2005, Contract Theory, MIT press.

[6] Clarida, Richard, Jordi Galí, and Mark Gertler, 2000, "Monetary Policy Rules and Macroeconomic Stability: Evidence and Some Theory," Quarterly Journal of Economics, 115(1), $147-80$.

[7] Danthine, Jean-Pierre and John B. Donaldson, 2008a, "Executive Compensation: A General Equilibrium Perspective", working paper, The Swiss Finance Institute.

[8] - and 2008b, "Executive Compensation and Stock Options: An Inconvenient Truth", working paper, The Swiss Finance Institute.

[9] Gabaix, Xavier and Augustin Landier, 2008, "Why Has CEO Pay Increased so Much?" Quarterly Journal of Economics, 123(1), 49-100.

[10] Jaimovich, Nir, 2007, "Firm Dynamics and Markup Variations: Implications for Multiple Equilibria and Endogenous Economic Fluctuations," Journal of Economic Theory, 137(1), 300-325.

[11] Jensen, Michael C. and Kevin J. Murphy, 1990, "Performance Pay and Top-Management Incentives," Journal of Political Economy, 98, 225-264.

[12] Jensen, Michael C., Kevin J. Murphy. and Eric G. Wruck, 2004, "Remuneration: Where We've Been, How We Got to Here, What Are the Problems, and How to Fix Them," Harvard NOM Working Paper No. 04-28.

[13] Hall, B. and K. Murphy, 2000, "Optimal Exercise Prices for Risk Averse Executives," American Economic Review, May, 209-214.

[14] Hall, Brian J. and K. Murphy, 2002, "Stock Options for Undiversified Executives," Journal of Accounting and Economics, 33, 3-42.

[15] Hansen, G., 1985, "Indivisible Labor and the Business Cycle," Journal of Monetary Economics, $16,309-327$.

[16] King, Robert G., Charles I. Plosser, and Sergio T. Rebelo, 1988, "Production, Growth and Business Cycles," Journal of Monetary Economics, 21, 195-232. 
[17] Laitner, John and Dmitriy Stolyarov, 2004, "Aggregate Returns to Scale and Embodied Technical Change: Theory and Measurement Using Stock Market Data," Journal of Monetary Economics, 51, 191-233.

[18] Lubik, Thomas A. and Frank Schorfheide, 2003, "Computing Sunspot Equilibria in Linear Rational Expectations Models," Journal of Economic Dynamics and Control, 28(2), 273-285.

[19] McGrattan, Ellen R. and Edward C. Prescott, 2007, "Unmeasured Investment and the Puzzling U.S. Boom in the 1990s," NBER Working Papers 13499.

[20] Murphy, Kevin J., 1999, "Executive Compensation," in Orley Ashenfelter and David Card (eds.), Handbook of Labor Economics, Vol. 3B, North Holland, 2485-2567.

[21] Murphy, Kevin J., 2002, "Explaining Executive Compensation: Managerial Power vs. the Perceived Cost of Stock Options," University of Chicago Law Review, 69, 847-869.

[22] Perli, Roberto, 1998, "Indeterminacy, Home Production, and the Business Cycle: A Calibrated Analysis," Journal of Monetary Economics, 41(1), 105-125.

[23] Schmitt-Grohe, Stephanie, 1997, "Comparing Four Models of Aggregate Fluctuations due to Self-Fulfilling Expectations," Journal of Economic Theory, 72, 96-147.

[24] Shleifer Andrei and Robert Vishny, 1997, "A Survey of Corporate Governance," Journal of Finance 52, 737-783.

[25] Sims, Christopher A., 2000, "Solving Linear Rational Expectations Models," manuscript, Princeton University.

[26] Stock, James H. and Mark Watson, 1999, "Business Cycle Fluctuations in U.S. Macroeconomic Time Series," in J.B. Taylor and M. Woodford (eds.), The Handbook of Macroeconomics, 1(1), 3-64, North-Holland.

[27] Wen, Yi,1998, "Capacity Utilization under Increasing Returns to Scale," Journal of Economic Theory, 81, 7-36.

[28] Woodford, Michael, 2003, Interest and Prices: Foundations of a Theory of Monetary Policy, Princeton, Princeton University Press. 
Table $1-$ Business Cycle Statistics ${ }^{(i)}$

\begin{tabular}{|c|c|c|c|c|}
\hline & $\begin{array}{c}\text { Panel A } \\
\text { U.S. data }{ }^{(i i)}\end{array}$ & $\begin{array}{c}\text { Panel B } \\
\text { Sunspot and } \\
\text { technology } \\
\text { shocks }\end{array}$ & $\begin{array}{c}\text { Panel C } \\
\text { Sunspot } \\
\text { shocks only }\end{array}$ & $\begin{array}{c}\text { Panel D } \\
\text { Hansen (1985) } \\
\text { divisible labor } \\
\text { economy }\end{array}$ \\
\hline \multicolumn{5}{|c|}{ Standard Deviations (in percent) $)^{(i i i)}$} \\
\hline$\sigma_{y}$ & 1.81 & 1.81 & 1.81 & 1.76 \\
\hline$\sigma_{k}$ & 0.63 & 0.54 & 0.95 & 0.47 \\
\hline$\sigma_{n}$ & 1.79 & 1.42 & 2.77 & 1.35 \\
\hline$\sigma_{i}$ & 5.30 & 5.62 & 9.90 & 5.71 \\
\hline$\sigma_{c^{s}}$ & 1.35 & 1.39 & 1.09 & 0.51 \\
\hline$\sigma_{c^{m}}$ & NA & 6.41 & 12.87 & NA \\
\hline$\sigma_{\varepsilon}($ tech. shock $)$ & NA & 1.04 & 0 & 0.71 \\
\hline$\sigma_{\nu}$ (sunspot shock) & NA & 4.81 & 9.62 & NA \\
\hline \multicolumn{5}{|c|}{ Contemporaneous Correlations with Output } \\
\hline$\rho_{k, y}$ & 0.06 & 0.23 & 0.37 & 0.05 \\
\hline$\rho_{n, y}$ & 0.88 & 0.65 & 0.98 & 0.98 \\
\hline$\rho_{i, y}$ & 0.80 & 0.83 & 0.99 & 0.99 \\
\hline$\rho_{c^{s}, y}$ & 0.88 & 0.64 & -0.87 & 0.87 \\
\hline$\rho_{c^{m}, y}$ & NA & -0.48 & -0.98 & NA \\
\hline
\end{tabular}

(i) The manager's contract is given by (17)-(18), with a share of fixed salary $A / \bar{c}^{m}=0.5$, and a weight of aggregate wage bill in the manager's compensation $\delta=0.1$. The convexity of the contract is $\theta=2$. The coefficient of the manager's risk aversion is $\eta_{m}=0.25$.

(ii) Source: Stock and Watson (1999).

(iii) Models' statistics are based on 500 simulations of sample size 200. Variables are expressed in log-deviations from the steady state and have been de-trended with the HP filter. 
Table 2 - Simulations with Alternative Parameterizations of the Managerial Contract ${ }^{(i)}$

\begin{tabular}{|c|c|c|c|c|}
\hline & $\begin{array}{l}\text { Panel A } \\
\text { Baseline }\end{array}$ & $\begin{array}{c}\text { Panel B } \\
\text { High contract } \\
\text { convexity } \\
\theta=3\end{array}$ & $\begin{array}{c}\text { Panel C } \\
\text { Large salary } \\
\text { component } \\
A / \bar{c}^{m}=0.7\end{array}$ & $\begin{array}{c}\text { Panel D } \\
\text { High manager's } \\
\text { risk aversion } \\
\eta_{m}=0.35\end{array}$ \\
\hline \multicolumn{5}{|c|}{ Standard Deviations (in percent) ${ }^{(i i)}$} \\
\hline$\sigma_{y}$ & 1.81 & 1.69 & 2.17 & 1.81 \\
\hline$\sigma_{k}$ & 0.54 & 0.39 & 0.82 & 0.54 \\
\hline$\sigma_{n}$ & 1.42 & 0.97 & 2.34 & 1.42 \\
\hline$\sigma_{i}$ & 5.62 & 4.26 & 8.66 & 5.64 \\
\hline$\sigma_{c^{s}}$ & 1.39 & 1.33 & 1.56 & 1.38 \\
\hline$\sigma_{c^{m}}$ & 6.41 & 6.42 & 6.46 & 6.45 \\
\hline$\sigma_{\varepsilon}$ (tech. shock) & 1.04 & 1.04 & 1.04 & 1.04 \\
\hline$\sigma_{\nu}($ sunspot shock $)$ & 4.81 & 4.81 & 4.81 & 4.81 \\
\hline \multicolumn{5}{|c|}{ Contemporaneous Correlations with Output } \\
\hline$\rho_{k, y}$ & 0.23 & 0.22 & 0.28 & 0.17 \\
\hline$\rho_{n, y}$ & 0.65 & 0.62 & 0.76 & 0.72 \\
\hline$\rho_{i, y}$ & 0.83 & 0.85 & 0.87 & 0.94 \\
\hline$\rho_{c^{s}, y}$ & 0.64 & 0.82 & 0.24 & 0.96 \\
\hline$\rho_{c^{m}, y}$ & -0.48 & -0.34 & -0.67 & -0.15 \\
\hline
\end{tabular}

(i) The manager's contract is given by (17)-(18). In Baseline parameterization, the share of fixed salary is $A / \bar{c}^{m}=0.5$, the weight of aggregate wage bill in the manager's compensation is $\delta=0.1$. The convexity of the contract is $\theta=2$. The coefficient of the manager's risk aversion is $\eta_{m}=0.25$.

(ii) Models' statistics are based on 500 simulations of sample size 200. Variables are expressed in log-deviations from the steady state and have been de-trended with the HP filter. 
$\left(\eta_{m}=0.25, \delta=0.2\right)$
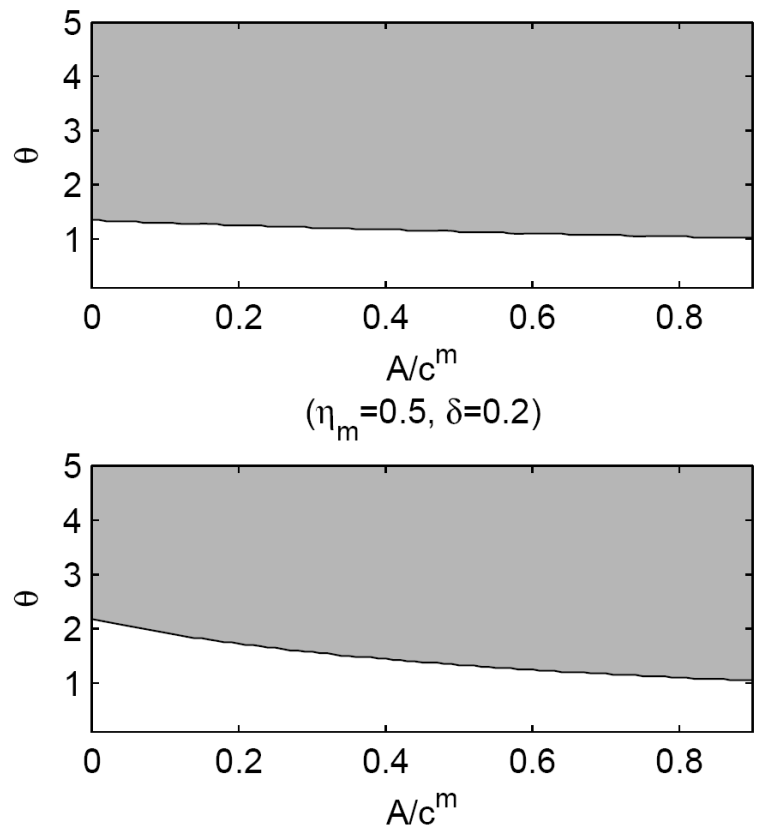

$\left(\eta_{\mathrm{m}}=1, \delta=0.2\right)$

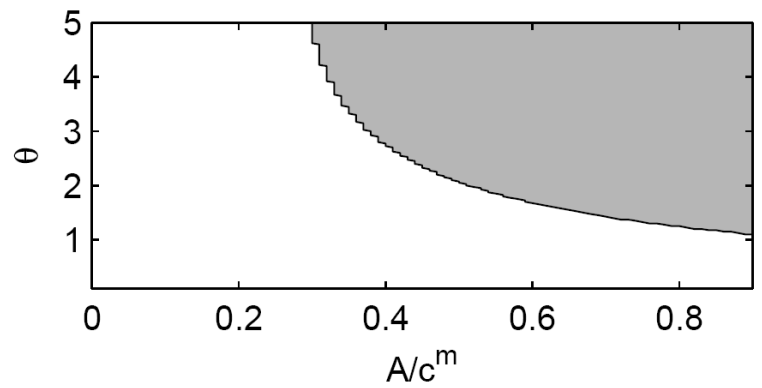

$\left(\eta_{m}=0.25, \delta=1\right)$

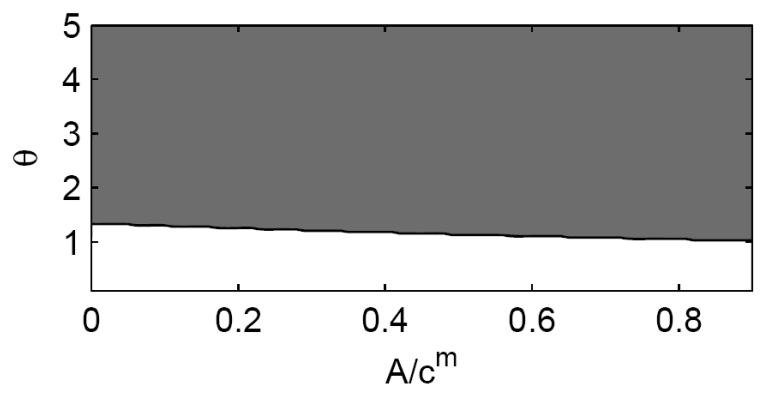

$\left(\eta_{m}=0.5, \delta=1\right)$

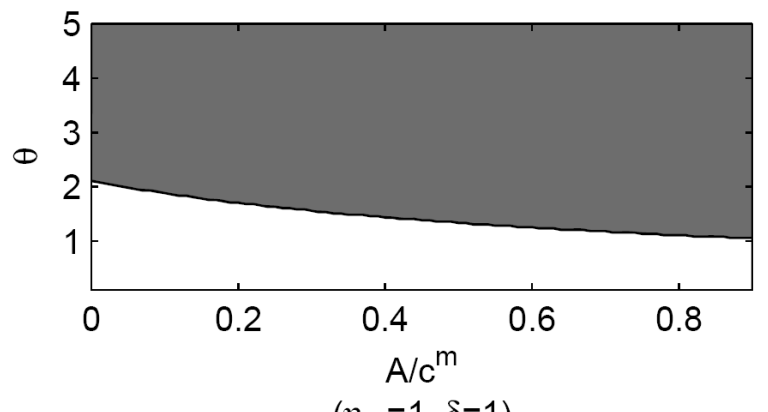

$\left(\eta_{m}=1, \delta=1\right)$

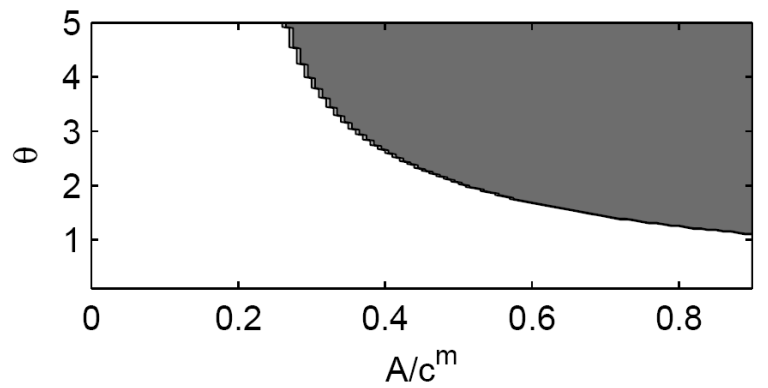

Figure 1: Regions of determinacy (white), indeterminacy (light gray) and instability (dark gray) in case of fixed labor supply (Frisch elasticity $\zeta^{-1}=0$ ) 
$\left(\eta_{m}=0.25, \delta=0.2\right)$

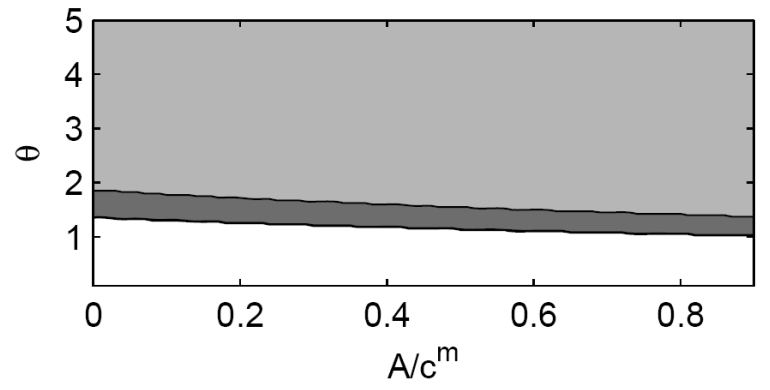

$\left(\eta_{\mathrm{m}}=0.5, \delta=0.2\right)$

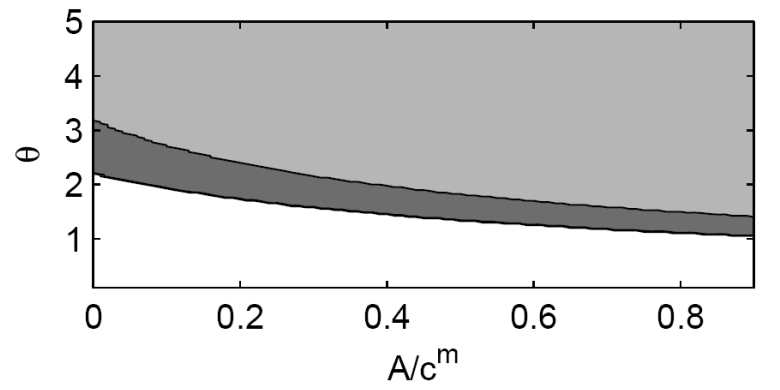

$\left(\eta_{m}=1, \delta=0.2\right)$

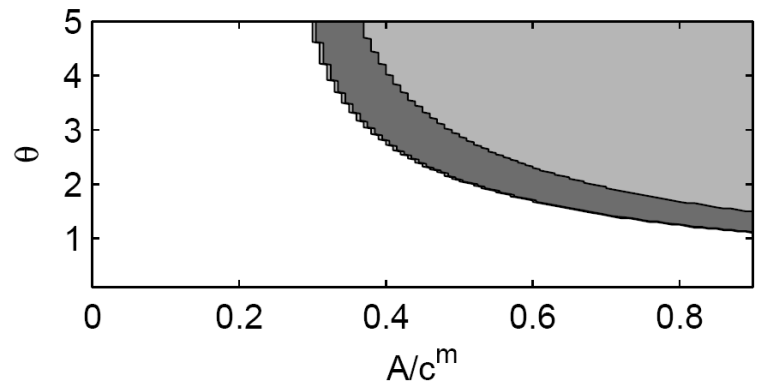

$\left(\eta_{m}=0.25, \delta=1\right)$

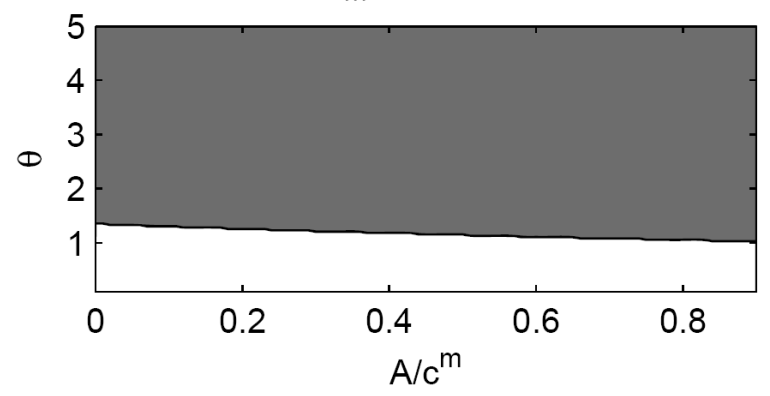

$\left(\eta_{m}=0.5, \delta=1\right)$

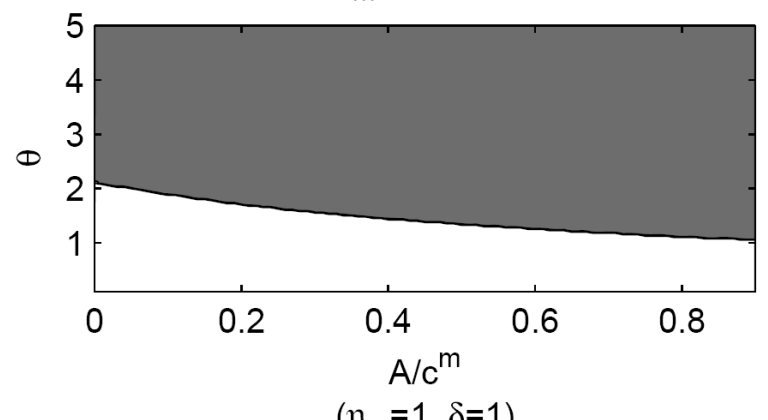

$\left(\eta_{m}=1, \delta=1\right)$

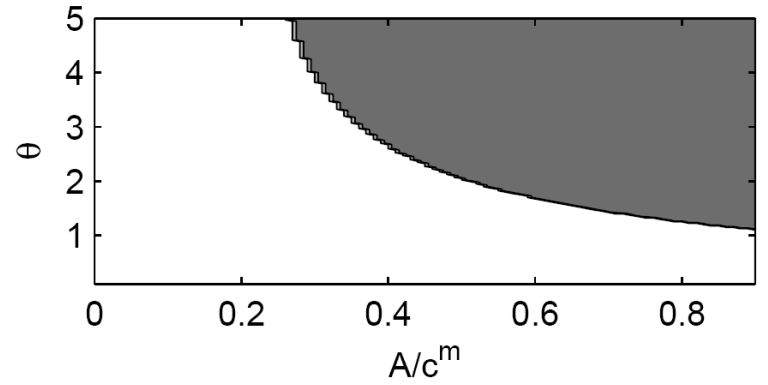

Figure 2: Regions of determinacy (white), indeterminacy (light gray) and instability (dark gray) in case of variable labor supply (Frisch elasticity $\zeta^{-1}=0.5$ ) 

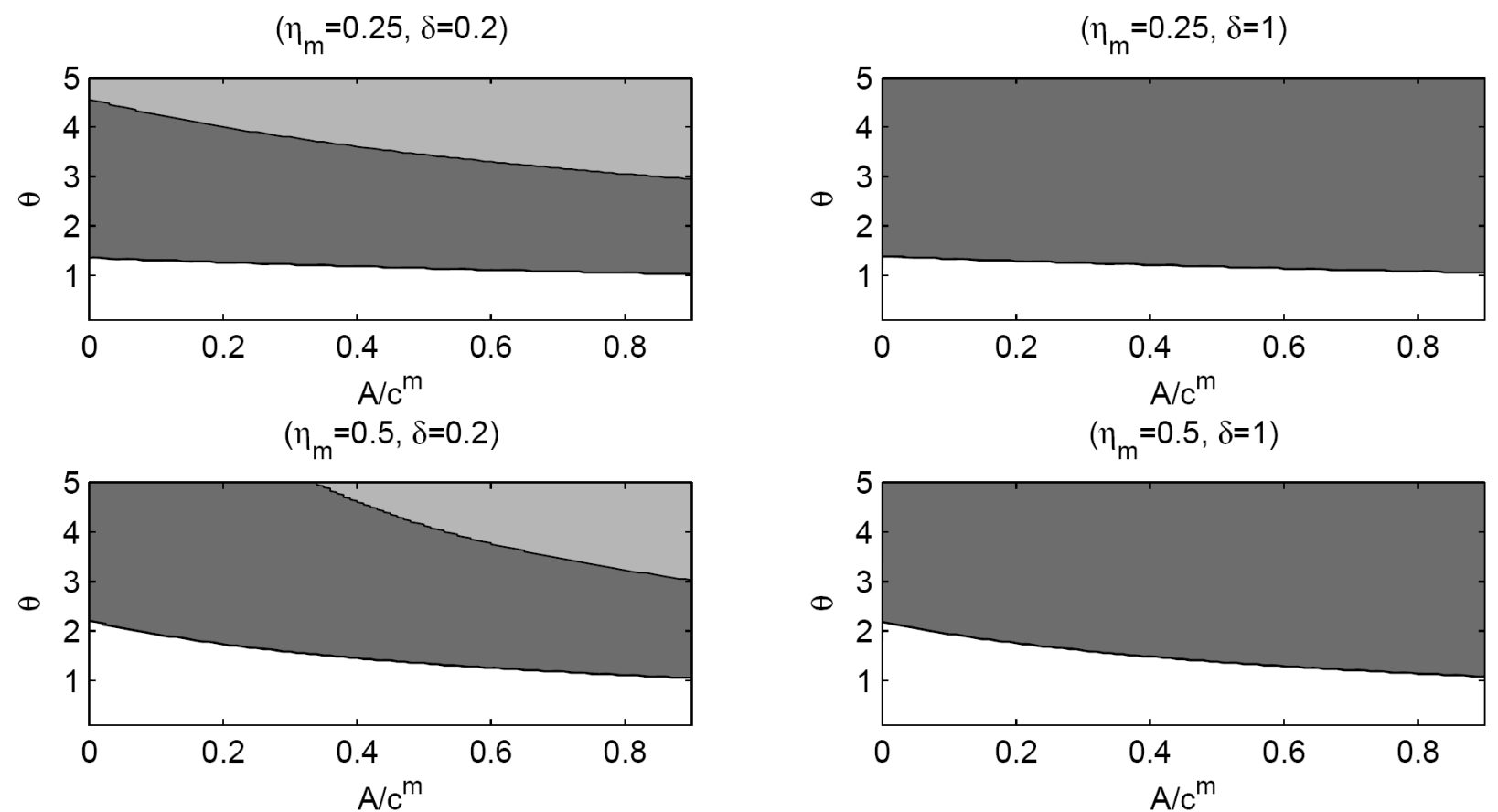

$$
\left(\eta_{m}=1, \delta=0.2\right)
$$
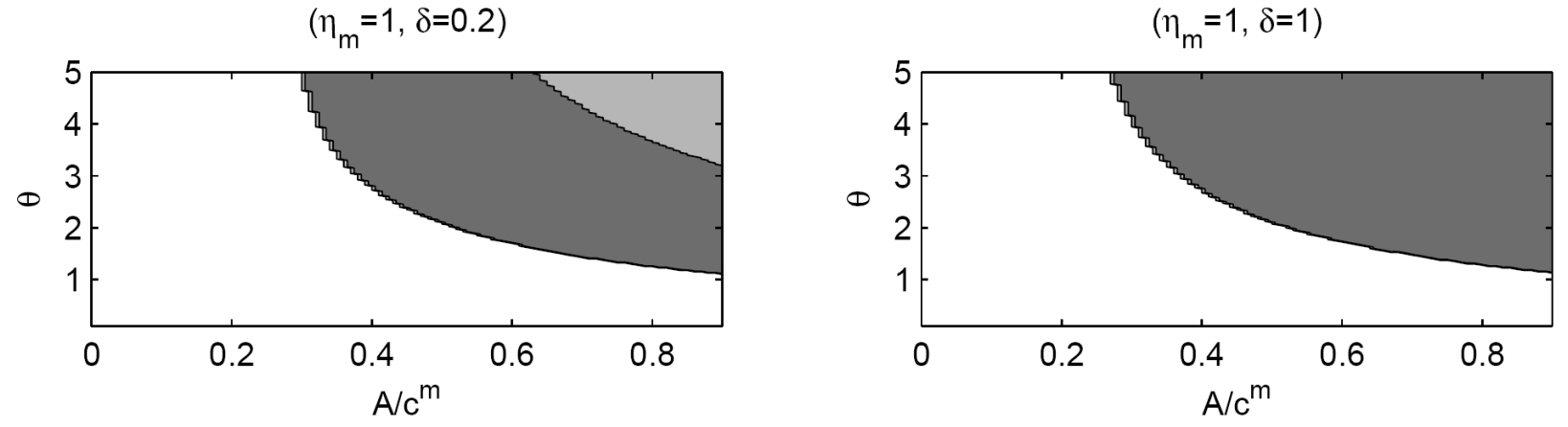

Figure 3: Regions of determinacy (white), indeterminacy (light gray) and instability (dark gray) with Hansen (1985) labor supply (Frisch elasticity $\zeta^{-1} \rightarrow \infty$ ) 


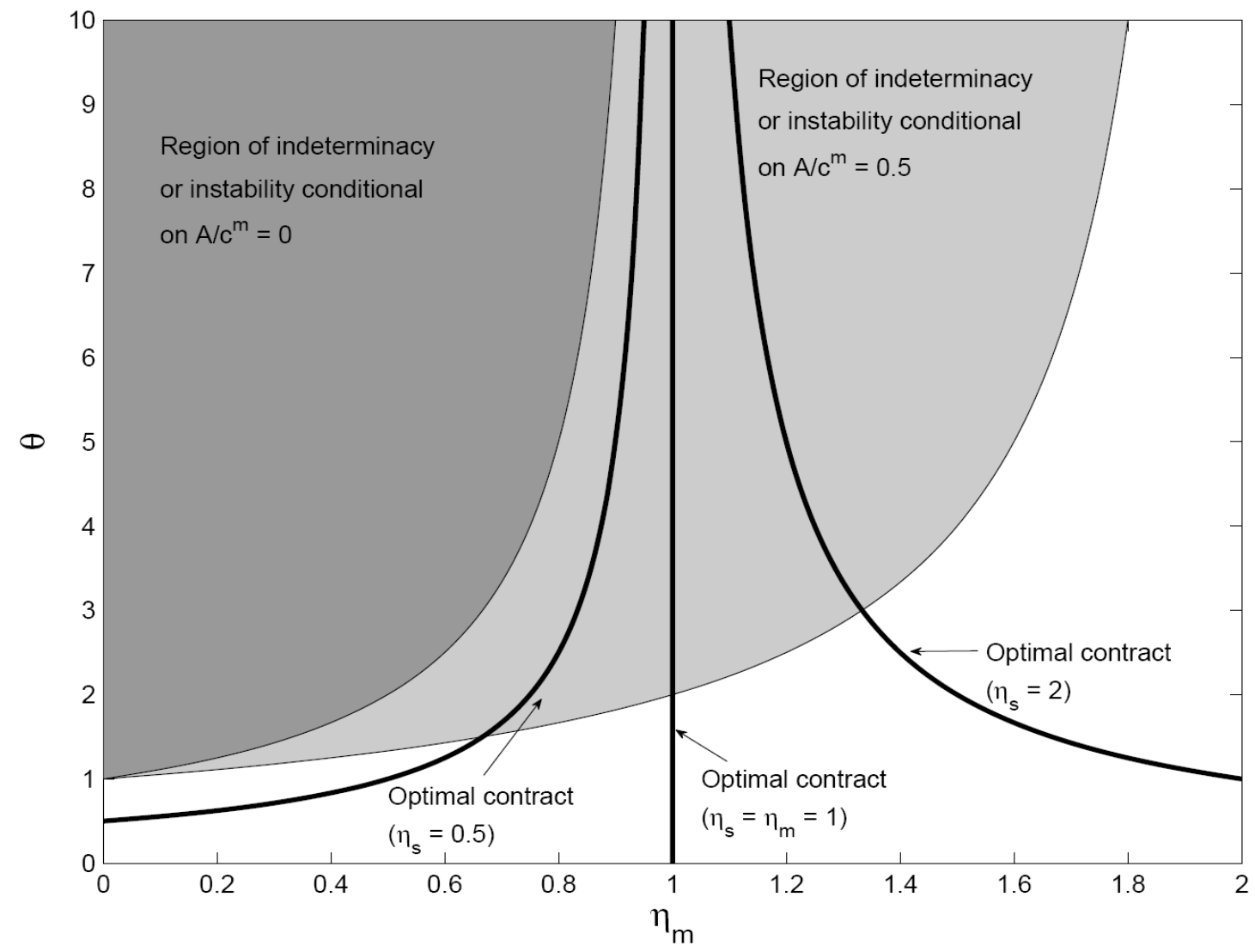

Figure 4: Regions of indeterminacy and instability, and optimal contract parameter combinations 